\title{
Safety and efficacy of autologous non- hematopoietic enriched stem cell nebulization in COVID-19 patients: a randomized clinical trial, Abu Dhabi 2020
}

Yendry Ventura-Carmenate ${ }^{1}$, Fatima Mohammed Alkaabi², Yandy Marx Castillo-Aleman, Carlos Agustin Villegas-Valverde ${ }^{1}$, Yasmine Maher Ahmed ${ }^{1}$, Pierdanilo Sanna', Ayesha Abdulla Almarzooqi², Abeer Abdelrazik', Gina Marcela Torres-Zambrano' ${ }^{1}$, Maura Wade-Mateo ${ }^{3}$, David Quesada-Saliba ${ }^{4}$, Loubna Abdel Hadi ${ }^{1}$, Antonio Alfonso Bencomo-Hernandez ${ }^{1}$ and Rene Antonio Rivero-Jimenez ${ }^{1 *}$

\begin{abstract}
Background: The novel SARS-CoV-2 has caused the coronavirus disease 2019 (COVID-19) pandemic. Currently, with insufficient worldwide vaccination rates, identifying treatment solutions to reduce the impact of the virus is urgently needed.

Method: An adaptive, multicentric, open-label, and randomized controlled phase I/II clinical trial entitled the "SENTAD-COVID Study" was conducted by the Abu Dhabi Stem Cells Center under exceptional conditional approval by the Emirates Institutional Review Board (IRB) for COVID-19 Research Committee from April 4th to July 31st, 2020, using an autologous peripheral blood non-hematopoietic enriched stem cell cocktail (PB-NHESC-C) administered by compressor (jet) nebulization as a complement to standard care therapy. The primary endpoints include safety and efficacy assessments, adverse events, the mortality rate within 28 days, and the time to clinical improvement as measured by a 2-point reduction on a seven-category ordinal scale or discharge from the hospital whichever occurred first.
\end{abstract}

Results: The study included a total of 139 randomized COVID-19 patients, with 69 in the experimental group and 70 in the control group (standard care). Overall survival was $94.20 \%$ for the cocktail-treated group vs. $90.27 \%$ for the control group. Adverse events were reported in 50 (72.46\%) patients receiving PB-NHESC-C and 51 (72.85\%) in the control group ( $p=0.9590$ ), with signs and symptoms commonly found in COVID-19. After the first 9 days of the intervention, $67.3 \%$ of cocktail-treated patients recovered and were released from hospitals compared to $53.1 \%$ ( $R R=0.84$; $95 \% \mathrm{Cl}, 0.56-1.28)$ in the control group. Improvement, i.e., at least a 2-point reduction in the severity scale, was more frequently observed in cocktail-treated patients (42.0\%) than in controls (17.0\%) $(\mathrm{RR}=0.69 ; 95 \% \mathrm{Cl}, 0.56-0.88)$.

Conclusions: Cocktail treatment improved clinical outcomes without increasing adverse events. Thus, the nebulization of PB-NHESC-C was safe and effective for treatment in most of these patients.

Trial registration: ClinicalTrials.gov. NCT04473170. It was retrospectively registered on July 16th, 2020.

Keywords: COVID-19, Stem cells, Nebulizers and vaporizers, Immunomodulation, Recovery of function

\footnotetext{
*Correspondence: rene.rivero@adscc.ae

1 Abu Dhabi Stem Cells Center, Al Misahah Street, Villa No. 25, Rowdhat, Zone-1, POB 4600, Abu Dhabi City, United Arab Emirates

Full list of author information is available at the end of the article
}

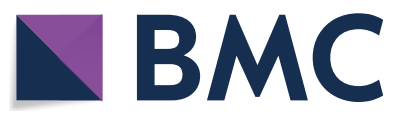

(c) The Author(s) 2021. Open Access This article is licensed under a Creative Commons Attribution 4.0 International License, which permits use, sharing, adaptation, distribution and reproduction in any medium or format, as long as you give appropriate credit to the original author(s) and the source, provide a link to the Creative Commons licence, and indicate if changes were made. The images or other third party material in this article are included in the article's Creative Commons licence, unless indicated otherwise in a credit line to the material. If material is not included in the article's Creative Commons licence and your intended use is not permitted by statutory regulation or exceeds the permitted use, you will need to obtain permission directly from the copyright holder. To view a copy of this licence, visit http://creativecommons.org/licenses/by/4.0/. 


\section{Introduction}

In December 2019, a novel member of the family of severe acute respiratory syndrome coronaviruses named SARS-CoV-2 rapidly spread from China throughout the globe, causing a pandemic of the human respiratory illness recognized as coronavirus disease 2019 (COVID-19) [1]. The United Arab Emirates (UAE) has shown a sharp and chaotic increase in the number of confirmed COVID-19 patients [2] despite the country's nationwide efforts to control the disease by introducing a series of strict measures to stop the spread of infection. After a noticeable surge of cases, the UAE declared a state of emergency to fight coronavirus, emphasizing the need for a new approach for treatment to decrease disease progression and related deaths.

SARS-CoV-2 infection can cause a broad spectrum of symptoms, ranging from mild to severe illness. COVID19 severe cases are characterized by severe pneumonia, acute respiratory distress syndrome (ARDS), excessive acute inflammatory responses, development of cytokine storms, and multiple organ failures leading to death. In contrast, non-severe cases present known clinical manifestations of respiratory system infection $[3,4]$. Although clinical aspects of COVID-19 patients have been widely reported and their management has increased tremendously, safe and effective medications are still lacking. Indeed, several clinical trials have been developed and are still under investigation for COVID19 prevention, treatment, and diagnosis [5-7].

Cellular therapy, a new field of medicine that uses cell-based products, is considered a pillar of regenerative and personalized medicine [8]. Different types of stem cells, including embryonic stem cells and adult stem cells, such as hematopoietic stem cells (HSCs), mesenchymal stem cells (MSCs), induced pluripotent stem cells (iPSCs), and, more recently, very small embryonic-like stem cells (VSELs), have been considered "candidates" in several therapies [9, 10]. Adult stem cells are somatic, rare, and undifferentiated populations located in their niches within several adult solid organs and play a key role in maintaining tissue homeostasis. Additionally, several studies have reported that adult stem cells, including VSELs, are self-renewing and multipotent, exist in a dormant state, and are recruited to the peripheral blood (PB) under an alarm recall to support the role of innate immunity $[11,12]$. Accordingly, adult stem cells are most likely present at high concentrations in the bloodstream of COVID-19 patients in response to exuberant inflammatory processes. However, good immune phenotyping of stem cells in the PB after SARS-CoV-2 infection is needed to develop potential cell therapeutic applications. To date, MSCs have shown a potential therapeutic effect in COVID-19. Several clinical trials have been registered for MSC-based therapies using different routes for delivery, including intravenous, intratracheal instillation, and inhalation/nebulization [13, 14].

Unfortunately, the challenge in adult stem cell therapy is the lack of well-established procedures for stem cell characterization, including cell isolation, purification, and expansion, without altering their phenotypes and functions [15]. To overcome these challenges, our group has developed a patented method for isolating an autologous peripheral blood non-hematopoietic enriched stem cell cocktail (PB-NHESC-C) [16] to be administered by the nebulization route.

The objective of this study was to assess the safety and efficacy of PB-NHESC-C stem cell cocktail nebulization as an add-on therapy to standard care for SARS-CoV2-infected patients during the COVID-19 outbreak in Abu Dhabi, UAE.

\section{Methods \\ Participants and study design}

The safety and efficacy of an autologous PB-NHESC-C in patients with COVID-19 were evaluated by an adaptive, multicentric, open-label, and randomized controlled phase I/II clinical trial called the "SENTAD-COVID Study". The Abu Dhabi Stem Cells Center (ADSCC) designed the study protocol and received exceptional conditional approval by the Ministry of Health and Prevention via the Emirates Institutional Review Board (IRB) for the COVID-19 Research Committee. It was performed in Abu Dhabi from April 4th to July 31st, 2020, using procedures based on ethical standards of the Helsinki Declaration of 1975 (as revised in 1983), such as informed consent for all participants. Patients of at least 15 different nationalities who resided in the emirate of Abu Dhabi were hospitalized and treated in four major government hospitals, with Sheikh Khalifa Medical City Hospital serving as the main primary care clinical trial unit. The study's sample size was established trying to detect a clinically significant difference between both groups concerning hospital stay and mortality with $80 \%$ power and a 5\% alpha error. Permuted block randomization was used to allocate patients to the treatment groups. Each "block" had a specified number of randomly ordered treatment assignments.

\section{Patients inclusion and exclusion criteria}

Inclusion: Real-Time Polymerase Chain Reaction (RTPCR) Laboratory confirmation of COVID-19; male or female aged $\geq 18$ years; Hospitalized and symptomatic patients, referring one or more of the following symptoms (fever, cough, or shortness of breath), in association with (at least one): tiredness, runny nose, 
headache, sore throat, chills, muscle pain, or new loss of taste or smell; Ability to comply with test requirements and for peripheral blood stem cells collection. Exclusion: Pediatric patients (aged < 18 years); Diagnosis of any shock; Organ transplants in the past 3 months; Patients receiving immunosuppressive therapy; Diagnostic of Hepatitis B Virus (HBV) infection; Diagnostic of Human Immunodeficiency Virus (HIV) infection or Acquired Immunodeficiency Syndrome (AIDS); Current diagnosis of cancer; History of malignancies in the past 5 years; Pregnant or lactating women; Having participated in other clinical trials in the past 3 months; Inability to provide informed consent. On the clinical site, selected investigators/physicians in charge of patient care communicated with the trial subjects.
When patients met the inclusion/exclusion criteria, they were recruited after they or their legal representative signed the informed consent. A doctoral supervisor approved collecting data from clinical records and an initial clinical evaluation. A total of 139 COVID-19 patients with HCoV-19 RNA confirmed by RT-PCR assay [17] were randomly included, as shown in Fig. 1.

Finally, patients were categorized according to their disease severity and clinical manifestations at the recruitment based on guidelines established by the interim guidance of the World Health Organization (WHO) as follows: scores of 1-2 represent patients in ambulatory conditions ( 1 indicates a completely asymptomatic patient, and 2 represents a patient with some limitation of activity); scores of 3-4 represent hospitalized patients

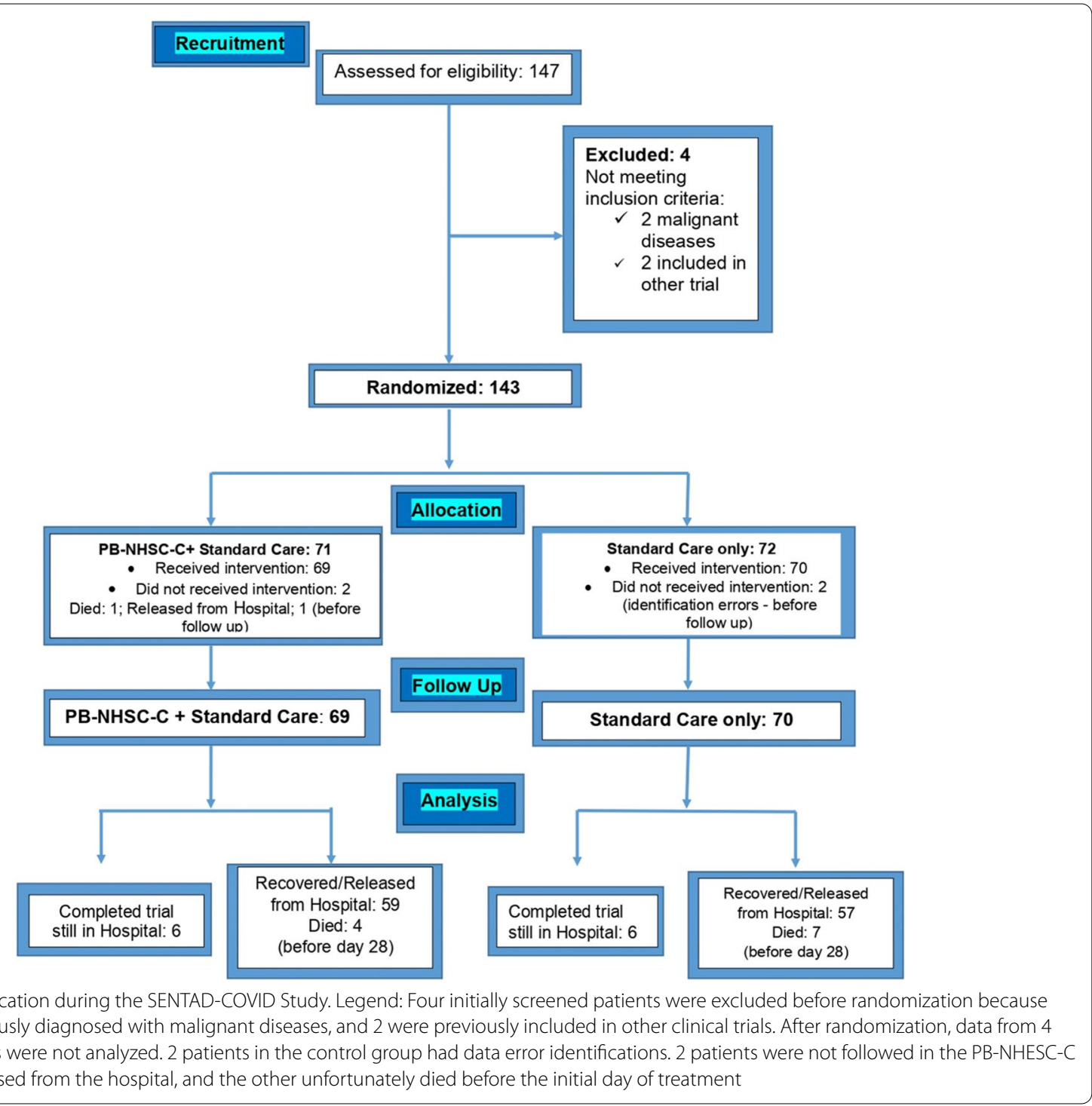


with mild disease (3 indicates a hospitalized patient without oxygen therapy, and 4 indicates a patient receiving oxygen by mass or nasal prongs); scores of 5-7 represent patients hospitalized with severe disease (5 represents a patient with no invasive ventilation or high flow oxygen, 6 represents a patient with intubation and mechanical ventilation, and 7 represents a patient under ventilation plus additional support, including vasopressor, renal replacement therapy, or extracorporeal membrane oxygenation); a score of 8 indicates a deceased patient [18].

\section{PB-NHESC-C: preparation, and characterization Preparation of the investigational product}

Briefly, autologous PB-NHESC-C was prepared in a closed system using a $300 \mathrm{~mL}$ collected of $\mathrm{PB}$ in quadruple blood bags (Haemonetics ${ }^{\circledR}, \mathrm{WBT}$ 436CCA, MA, USA). First, the bags were centrifuged in a Hettich centrifuge (Roto Silenta 630 RS, Tuttlingen, FRG) at $800 \times \mathrm{g}$ to obtain platelet and stem cells rich plasma. Next, centrifugation separated the platelet-concentrated plasma (PCP) from the stem cells. Finally, PCP was used to produce platelet-derived growth factor (PDGF) by sonication. Stem cells were suspended in $30 \mathrm{~mL}$ of PDGF to obtain the cocktail and stored at $4-8^{\circ} \mathrm{C}$ for $24 \mathrm{~h}$ before clinical application, which could be performed within 5 days after its preparation [16]. The final investigational product keeps viability between 90 and $95 \%$ up to 10 days stored at $4-8^{\circ} \mathrm{C}$.

\section{Flow Cytometry analysis}

The stem cells cocktail was characterized by identifying hematopoietic stem cells subsets expressing $\mathrm{CD} 34^{+}$, $\mathrm{CD}_{133^{+}}, \mathrm{CD}^{+} 0^{+}, \mathrm{CD} 45^{+}$, and non-hematopoietic stem cells identified as CD45 negative using a Navios EX flow cytometer (Beckman Coulter, USA). Then, $100 \mu \mathrm{L}$ of PBNHESC-C was dispensed for staining with fluorochromeconjugated monoclonal antibodies from the same manufacturer: Krome Orange (Kro) anti-CD45 (Kro, clone J33); Pacific-blue (Pb) anti-CD90 (Pb, clone Thy1/310); Allophycocyanin (APC) anti-CD133 (APC, clone W6B3C1); and R-Phycoerythrin-Texas $\operatorname{Red}^{\circledR}-\mathrm{X}$ (ECD) anti-CD34 (ECD, clone 581). Cell viability was evaluated with 7-amino actinomycin D (7-AAD) to exclude dead cells from analysis. After $30 \mathrm{~min}$ of incubation at room temperature (RT) in the dark, cells were treated for 10 min with $500 \mu \mathrm{L}$ of OptiLyse C. Before an immediate running, $100 \mu \mathrm{L}$ flow-count fluorospheres were added for absolute cell counts. Angiotensin-Converting Enzyme 2 (ACE2) Surface Expression Determination: $100 \mu \mathrm{L}$ of PB-NHESC-C were incubated for $20 \mathrm{~min}$ in the dark with $20 \mu \mathrm{L}$ of the anti-CD45 (Kro; clone J33), $20 \mu \mathrm{L}$ of $7-\mathrm{AAD}$, and $5 \mu \mathrm{L}$ of anti-CD143 (APC; clone 5-369, Biolegend). Acquisition data were processed using Kaluza C Software
V1.1 with a minimum of 150,000 acquired events. The gating strategy is shown in Fig. $2 \mathrm{~A}$.

\section{Immunofluorescence analysis}

Samples of PB-NHESC-Cs were fixed with $3.5 \%$ paraformaldehyde for $20 \mathrm{~min}$, pre-blocked with $2 \%$ bovine serum albumin for $10 \mathrm{~min}$ at RT, and subsequently stained with fluorescein isothiocyanate (FITC)-conjugated CD45 (1:100, mouse monoclonal IgG; Beckman Coulter) for $30 \mathrm{~min}$ at RT in the dark. Hoechst 33342 nucleic acid stain (Sigma Aldrich) was added at $10 \mu \mathrm{g} / \mathrm{mL}$ to the cell suspensions for $20 \mathrm{~min}$ at RT in the dark. After washing, PB-NHESC-C was acquired using a laser scanning microscope (Leica SP8 confocal microscope, Leica) with FITC (emission 496-598 nm) and Hoechst (emission $415-470 \mathrm{~nm}$ ) channels using a $60 \mathrm{x}$ objective.

\section{SARS-CoV-2 antibody detection}

SARS-CoV-2 antibody levels were assessed in 63 PDGF samples of treated patients (13 severe cases; 50 moderate cases) using semiquantitative Ortho VITROS $^{\circledR}$ AntiSARS-CoV-2 Total (CoV2T) and Anti-SARS-CoV2-IgG (CoV2G) antibodies (Ortho Clinical Diagnostics, Raritan, New Jersey) and analyzed using the VITROS ECi/ECiQ 3600 Immunodiagnostic System following the manufacturer's instructions. The results were reported as either reactive $(\mathrm{S} / \mathrm{CO} \geq 1.0)$ or nonreactive $(\mathrm{S} / \mathrm{CO}<1.0)$, and the $\mathrm{S} / \mathrm{CO}$ was obtained using the manufacturer system [19].

\section{PDGF metabolite measurement}

We determined PDGF concentrations in 20 stem cells cocktail samples from COVID-19 patients. PDGF included: Angiopoietin-2 (Ang-2), epidermal growth factor (EGF), erythropoietin (EPO), fibroblast growth factor (FGF-basic), granulocyte-colony stimulation factor (G-CSF), granulocyte/macrophage-colony stimulation factor (GM-CSF), hepatocyte growth factor (HGF), macrophage-colony stimulation factor (M-CSF), platelet-derived growth factor AA (PDGF-AA), plateletderived growth factor-BB (PDGF-BB), stem cell factor (SCF), T-cell growth factor-alpha (TGF- $\alpha$ ), and vascular endothelial growth factor (VEGF). PDGF metabolite concentrations were determined using a 13-plex bead-based multiplex assay kit (LEGENDplex ${ }^{\text {TM }}$ Human Growth Factor Panel; Cat. No. 740180) by fluorescence intensity in a Navios EX cytometer and analyzed with LEGENDplex V.8.0 software as recommended by the manufacturer.

\section{Treatment procedures and follow-up}

PB-NHESC-C was delivered to the patients of Group A following compressor (jet) nebulization for a total of two doses $24 \mathrm{~h}$ apart. Both doses were administered through a sterile humidifier and a regular concentrated oxygen 

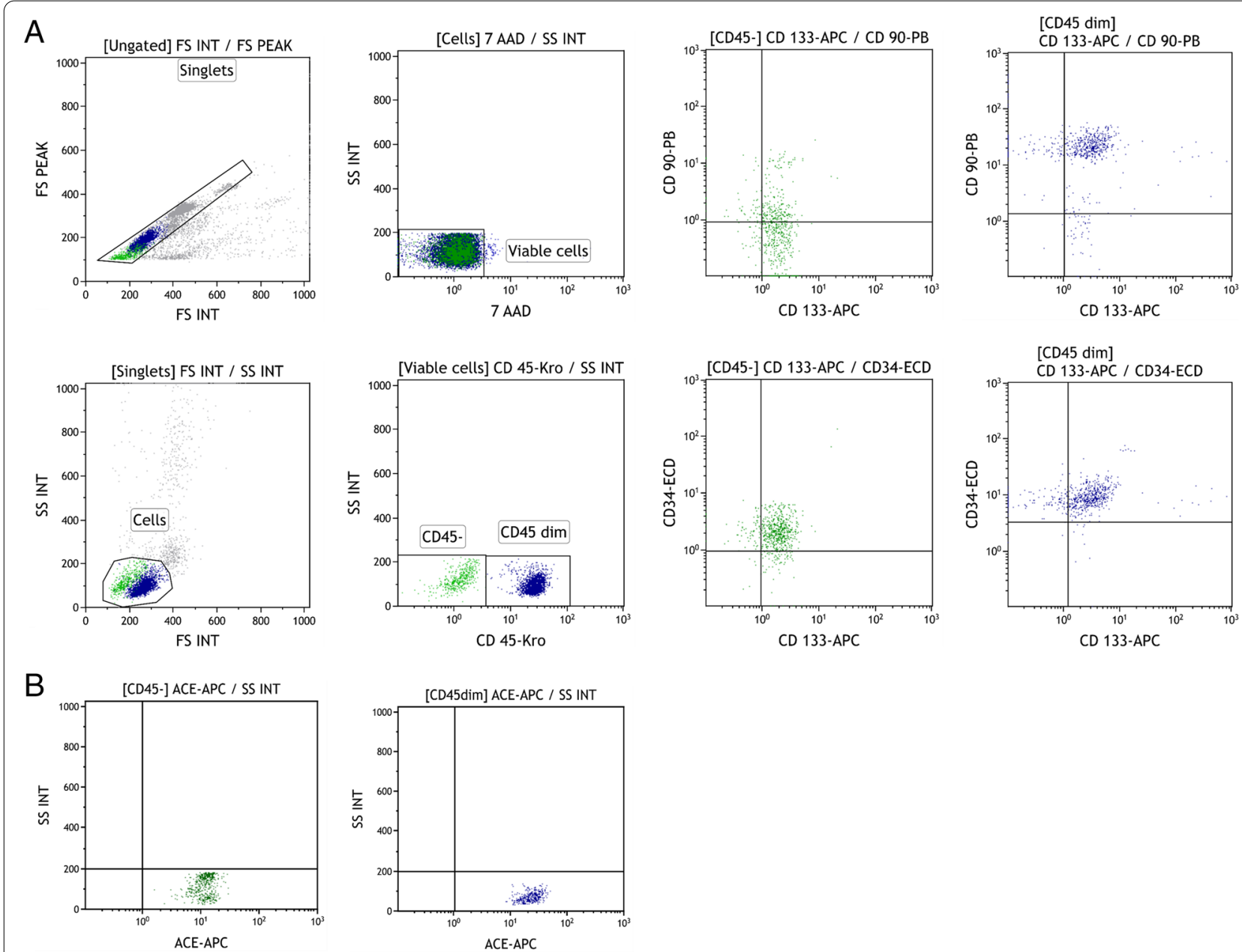

Fig. 2 Flow cytometry gating strategy. Legend: Immunophenotype characterization of peripheral blood non-hematopoietic enriched stem cell cocktail. 2A) Logic and manual gating strategy for cell characterization using five monoclonal antibody-conjugated CD markers simultaneously, including 7-Amino-Actinomycin D (7-AAD). 2B) Expression of angiotensin-converting enzyme 2 (ACE2)

supply at a flow rate of $5-6 \mathrm{~L} / \mathrm{min}$. For clinical and laboratory evaluations, stem cell treatments were performed on days 0 and 1 , and daily follow-up was performed for 28 days. Group B (control) was treated exclusively with the standard care provided to both groups.

All clinical, laboratory and radiological data were recorded during patient follow-up. From a clinical point of view, a detailed record included primary safety data (nebulization or standard treatment-induced allergic reactions, secondary infection, and severe and nonsevere adverse events), and efficacy data were reported for the measurement of endpoints. Laboratory tests: a complete blood count determined using a Hematology Analyzer DHX900 (Beckman Coulter, USA) and acute phase reactants, such as $\mathrm{C}$-reactive protein (CRP), which was assessed using a Chemistry Analyzer AU480 (Beckman Coulter, USA), and fibrinogen and D-dimer, which were assessed using a Cobas t 511 (Roche, Switzerland), according to the manufacturer's instructions and in compliance with ADSCC standard operating procedures (SOP). SARS-CoV-2 RNA was assessed by real-time reverse transcription PCR before recruitment and after treatment [17]. Radiology: Both groups were followed using different imaging approaches, like X-rays and computer tomography scans (CT) until discharge, considering proposed recommendations for COVID-19 patients [20]. Forty CT were evaluated according to the critical criteria indicated using GE 46 Multi-Slice Computer Tomography (MSCT) (General Electric Healthcare System, USA).

\section{Outcomes evaluation}

Primary safety data: adverse effects and disease assessment

Adverse events were assessed using the "Common Terminology Criteria for Adverse Events (CTCAE) v5.0" 
[21]. Group A patients were closely followed up for possible acute adverse events of treatment (AET) during the first 3 days after receiving stem cell nebulization. This follow-up continued for 28 days. AET in the control group was also evaluated during the same period.

\section{Primary endpoints}

a) Hospital discharge. Assessed after the first 9 days of randomization: (1st. tertile of the follow-up).

b) Mortality. Death by any cause in the 28 days of follow-up.

\section{Secondary endpoints}

a) Accelerated clinical improvement after 9 days (1st. tertile of follow-up): Defined as a net decrease of at least 2 points on the scale (excluding patients who experienced increases in points in the period analyzed).

b) Clinical improvement after 9 days (1st. tertile of follow-up). Defined as a net decrease of at least one point on the scale (excluding patients who experienced increases in points in the period analyzed).

\section{Exploratory endpoints}

a) The persistence of lymphopenia.

b) The appearance of lymphopenia.

c) The persistence of an elevated neutrophil/lymphocyte ratio (NLR).

d) The persistence of high C-reactive protein (CRP) levels.

e) The persistence of elevated D-dimer levels (in the stem cell treated group).

All assessments were performed on the day of randomization and 5 days (1st quintile) after the intervention. Control group: evaluated on the day of randomization and 6 days later.

\section{Statistical analysis}

Efficacy was assessed in the intention-to-treat and safetyas-treated groups in the study population. All statistical tests were performed to demonstrate the superiority of the assessed experimental therapy against the standard of care established for COVID-19. The Shapiro-Wilk test was performed to assess the normality of data distribution. The Mann-Whitney U non-parametric test was used for the analysis of two independent groups. Spearman's rho correlation was applied in the comparison of downward changes in scores. The Wilcoxon test for nonparametric paired samples in laboratory variables before and after interventions as well as Fisher's exact probability test for a small number of samples were also applied in the adverse events comparison, whereas the Chi-square test was used for categorical data, such as in the comparison of patient demographics and clinical proportions, adverse events and some laboratory variable analyses. To evaluate the clinical impact of interventions, the relative risk (RR) was calculated with a $95 \%$ confidence interval $(\mathrm{CI})$, the relative risk reduction (RRR), and the number needed to treat (NNT) were also analyzed. Most of the statistical analyses were performed with GraphPad Prism v.8 (La Jolla, America) [22] and MedCalc software [23]. All $p$-values represented were two-sided and considered statistically significant when $p<0.05$.

\section{Results}

\section{Patient groups}

Figure 1 shows the number of patients initially assessed for eligibility, the excluded ones, the randomized allocations into two groups, and patients receiving the different interventions and their follow-up and final analysis and outcomes. The main demographic and clinical status of the COVID-19 patients are shown in Table 1.

Finally, 143 SARS CoV-2 confirmed by PCR patients were randomized, but only 139 were selected for the intervention (Fig. 1). Group A included 69 patients $(65$ males, four females) aged $45.93 \pm 9.75$ years old (mean $\pm \mathrm{SD}$; minimum 27 , maximum 71 ) to assess the investigational product plus the standard COVID-19 care treatment established by the Ministry of Health and Prevention of the United Arab Emirates (MOHAP) [24]. Group B served as the control group with 70 patients (64 males, six females) aged $44.31 \pm 11.22$ years old (mean \pm SD; minimum 26 , maximum 73 ), recruited from the same hospitals, and receiving the standard care for COVID-19 exclusively. The standard care treatment for patients allocated to groups A and B included the following medication at baseline: Favipiravir, Lopinavir/Ritonavir or combined use of both drugs, as antivirals co-intervention in more than $82 \%$ of cases; Enoxaparin as an anticoagulant in 56\% of cases; Tocilizumab as immunotherapy medications in $5 \%$ of cases; Hydroxychloroquine in the $89 \%$ of cases; and hydrocortisone in only three patients of group A as corticosteroids. In addition, antibiotics, antihypertensive and hypoglycemic drugs were applied in need cases.

The clinical score on the day of randomization was taken as a reference for the clinical follow-up. The composition of analyzed patients was 44 with severe disease: 31 critically ill (score 7), 13 severe patients (scores 5 and 
Table 1 Demographic data and clinical status of the enrolled patients on the recruitment day

\begin{tabular}{|c|c|c|c|}
\hline Parameter & $\begin{array}{l}\text { Group A: Treated with PB-NHESC-C plus } \\
\text { standard care }(n=69)\end{array}$ & $\begin{array}{l}\text { Group B: Control (standard care } \\
\text { only) }(n=70)\end{array}$ & $p$-Value \\
\hline \multicolumn{4}{|l|}{ Demographic data } \\
\hline Age, years (mean $\pm S D$ ) & $45.93 \pm 9.75$ & $44.38 \pm 11.09$ & 0.380 \\
\hline \multicolumn{4}{|l|}{ Gender, n (\%) } \\
\hline Total & $69(48.94)$ & $70(51.06)$ & \\
\hline Masculine & $65(46.10)$ & $64(46.81)$ & 0.7447 \\
\hline Feminine & $4(2.88)$ & $6(4.32)$ & \\
\hline \multicolumn{4}{|l|}{ Nationalities } \\
\hline Afghanistan & $2(2.90)$ & $1(1.43)$ & 0.6195 \\
\hline Bangladesh & $11(15.94)$ & $11(15.71)$ & 1.0000 \\
\hline China PRP & $0(0)$ & $1(1.43)$ & 1.0000 \\
\hline Egypt & $3(4.35)$ & $3(4.29)$ & 1.0000 \\
\hline India & $22(31.88)$ & $28(40.00)$ & 0.2920 \\
\hline Indonesia & $1(1.45)$ & $0(0)$ & 0.4964 \\
\hline Jordan & $0(0)$ & $1(1.43)$ & 1.0000 \\
\hline Nepal & $5(7.25)$ & $2(2.86)$ & 0.2746 \\
\hline Pakistan & $10(14.49)$ & $15(21.43)$ & 0.3777 \\
\hline Palestine & $4(5.80)$ & $0(0)$ & 0.0581 \\
\hline Philippines & $4(5.80)$ & $4(5.71)$ & 1.0000 \\
\hline Somalia & $1(1.45)$ & $0(0)$ & 0.4964 \\
\hline Sudan & $3(4.35)$ & $0(0)$ & 0.1196 \\
\hline Syria & $1(1.45)$ & $2(2.86)$ & 1.0000 \\
\hline UAE & $1(1.45)$ & $1(1.43)$ & 1.0000 \\
\hline USA & $0(0)$ & $1(1.43)$ & 1.0000 \\
\hline Unknown & $1(1.45)$ & $0(0)$ & 0.4964 \\
\hline \multicolumn{4}{|l|}{ Health status at recruitment } \\
\hline \multicolumn{4}{|l|}{ Body mass index categories, n (\%) } \\
\hline Unknown & $3(4.35)$ & $2(2.86)$ & 0.6806 \\
\hline Normal (healthy weight) & $17(24.64)$ & $29(41.43)$ & $0.0472^{\mathrm{a}}$ \\
\hline Overweight & $35(50.74)$ & $19(27.14)$ & $0.0054^{b}$ \\
\hline Obese Class I (moderately obese) & $11(15.94)$ & $13(18.57)$ & 0.8230 \\
\hline Obese Class II (severely obese) & $0(0)$ & $3(4.29)$ & 0.2446 \\
\hline Obese Class III (very severely obese) & $3(4.35)$ & $4(5.71)$ & 1.0000 \\
\hline \multicolumn{4}{|l|}{ Moderate COVID- 19, n (\%) } \\
\hline Score 3 & $37(53.62)$ & $40(57.14)$ & 0.7342 \\
\hline Score 4 & $12(17.39)$ & $6(8.57)$ & 0.1372 \\
\hline Subtotal & $49(71.01)$ & $46(65.71)$ & 0.5852 \\
\hline \multicolumn{4}{|l|}{ Severe COVID-19, n (\%) } \\
\hline Score 5 & $3(4.34)$ & $7(10.00)$ & 0.3255 \\
\hline Score 6 & $2(2.89)$ & $1(1.42)$ & 0.6195 \\
\hline Score 7 & $15(21.74)$ & $16(22.86)$ & 1.0000 \\
\hline Subtotal & $20(28.98)$ & $24(34.28)$ & 0.5852 \\
\hline \multicolumn{4}{|l|}{ Main comorbidities, n (\%) } \\
\hline Arterial hypertension & $18(26.09)$ & $19(27.14)$ & 1.0000 \\
\hline Diabetes mellitus & $18(26.09)$ & $13(18.57)$ & 0.3142 \\
\hline Cardiovascular disease and dyslipidemia & $7(6.25)$ & $6(8.57)$ & 0.7792 \\
\hline Chronic smoking and asthma & $11(15.94)$ & $4(5.71)$ & 0.0603 \\
\hline
\end{tabular}

PB-NHESC-C: peripheral blood non-hematopoietic enriched stem cell cocktail; the $p$-value for age was determined by a $x^{2}$-test; the remaining $p$-values were determined by the F-exact probability test; ${ }^{a}$ : significant difference; ${ }^{\text {b }}$ : highly significant difference 
6), and 95 moderate COVID-19 (score 3: $n=77$, and score $4: n=18$ ). The conformation of the two arms for the trial was not statistically different in score and number of patients by Fisher's exact probability test, as shown in Table 1.

\section{PB-NHESC-C characterization}

The PB-NHESC-C was characterized by flow cytometry (Fig. 2A) and two main cell fractions with greater than $95 \%$ viability were noted: hematopoietic stem cells $\left(C D 45^{\mathrm{dim}}\right)$ in the range of $25-49 \%$ (median 36\%) and non-hematopoietic stem cells $\left(\mathrm{CD} 45^{-}\right)$in the range of $53-70 \%$ (median 64\%) with one or more of the following markers: $\mathrm{CD}_{133^{+}}, \mathrm{CD} 90^{+}$and $\mathrm{CD} 34^{+}$. The PB-NHESC$\mathrm{C}$ also contains anti-SARS-CoV-2 antibodies and PDGF. The median total number of nebulized cells was $2.2 \times 10^{6}$ for the whole group of treated patients, $1.8 \times 10^{6}$ among severe COVID-19 patients, and $2.5 \times 10^{6}$ in moderate cases. PB-NHESC-C was predominated comprised of $\mathrm{CD} 45^{-} / \mathrm{CD} 133^{+}$and $\mathrm{CD} 34^{+}$cells. CD $45^{\text {dim }}$ cell counts were significantly higher in moderate cases compared with severe ones $(p<0.0001)$, and the $\mathrm{CD} 45^{-}$cell count was higher in severe cases compared with moderate ones, but not statistically significant $(p=0.6)$. A positive correlation was observed between the patient's absolute lymphocyte count and the number of $\mathrm{CD} 45^{\mathrm{dim}}$ cells in PB-NHESC-C $(p=0.006)$ and its absence with respect to $\mathrm{CD} 45^{-}$cells $(p=0.79)$. The $\mathrm{CD} 45^{-} / \mathrm{CD}^{+} 0^{+}$marker predominated in the PB-NHESC-C of severe patients compared with moderate patients $(p=0.04)$, as shown in Table 2.

ACE2 receptor expression was demonstrated in all $\mathrm{CD}^{-} 5^{-}$and CD45 ${ }^{\text {dim }}$ cells (Fig. 2B). On the other hand, the presence of anti-SARS-CoV-2 total antibodies (COV2T) was detected in all cocktail samples of severe patients and $94 \%$ of moderate cases $(p=0.36)$. IgG antiSARS-CoV-2 antibodies (COV2G) were more frequently observed $(84.3 \%)$ in the autologous preparations of severe compared with moderate patients $(48 \%)(p=0.01)$. The semiquantitative values of total anti-CoV-2 (102.0 vs. $16.4, p=0.007)$ and anti-anti-CoV-2 IgG (6.9 vs. 1.6 , $p=0.005)$ were higher in severe cases than moderate cases. Therefore, the characterization of samples from PB-NHESC-C showed the presence of human PDGF derived from autologous PCP. PDGF-AA and M-SCF exhibited the highest concentrations, followed by PDGFBB, EGF, Ang-2, and HGF, as shown in Table 2.

In addition, after the isolation of stem cells from the $\mathrm{PB}$ of patients, a representative image of PB-NHESC$\mathrm{C}$ shows a slightly higher number of very small CD45 negative $\left(\mathrm{CD} 45^{-}\right)$cells with a diameter of approximately
5-7 $\mu \mathrm{m}$, compared with the fraction of cells dimly stained with CD45 (CD45 $\left.{ }^{\mathrm{dim}}\right)$ (Fig. 3).

\section{Outcomes}

Primary safety data: assessment of adverse events and safety Patients with adverse events were reported from both groups, with 101 (72.66\% of enrolled patients) were affected. In total, 50 (72.46\%) patients received stem cell treatment compared to $51(72.85 \%)$ patients in the control group $(p=0.9419)$. A total of 240 adverse events were reported during the 28-day follow-up for all enrolled patients (Table 3).

Serious events, including patient death, were assessed. In total, 35 serious events occurred in the PB-NHESC-Ctreated group, and 57 were noted in the control group.

\section{Primary endpoints: PB-NHESC-C treatment partially demonstrated superior effects on hospital discharge and mortality reduction}

Hospital discharge After 9 days of follow-up (evaluating the first tertile after cell therapy), 63.3\% of PB-NHESCC-treated patients recovered and were discharged from hospitals. In the control group, this percentage was only $57.1 \%$, but a nonsignificant difference was found. In addition, this patient's hospital discharge after the first 9 days was related to a higher dose of $\mathrm{CD} 45^{\mathrm{dim}} / \mathrm{CD} 34^{+}$phenotype $\left(1.4 \times 10^{6}\right.$ vs. $\left.0, p=0.0002\right)$ compared to the rest of non-discharged patients.

Mortality reduction Although the outpoint regarding mortality reduction after 28 days of follow-up was not achieved, in the PB-NHESC-C treated group, the proportion of $5.8 \%$ death patients was lower than the $9.73 \%$ in the control group, but it was not statistically significant $(p=0.5319)$.

\section{Secondary endpoints: clinical improvement over time due to PB-NHESC-C treatment observed in severe and moderate COVID-19 patients}

From a clinical point of view, as seen in Fig. 4, severe COVID-19 patients treated with PB-NHESC-C resulted in more rapid clinical improvement than the corresponding control subgroup, as measured by the number of patients with clinical scores reductions daily. A trend line was noted in the score changes of this subgroup of stem cell-treated COVID-19 patients. The control evaluation yielded a highly significant difference in lines slopes between both groups $(p \leq 0.0001)$. Stem cell-treated moderate COVID-19 patients also improved and showed a linear trend compared with the equivalent controls with 
Table 2 Cellular and humoral components of the peripheral blood non-hematopoietic enriched stem cell cocktail

\begin{tabular}{|c|c|c|c|c|}
\hline Cellular elements, median (range) & Severe cases $(n=19)$ & Moderate cases $(n=50)$ & Total $(n=69)$ & $p$-value \\
\hline Total stem cell dose $\left(\times 10^{6}\right.$ cells $)$ & $1.8(0.2-12)$ & $2.5(0.4-23)$ & $2.2(0.4-23)$ & 0.34 \\
\hline \multicolumn{5}{|l|}{ Cellular CD markers $\left(\times 10^{5} \text { cells }\right)^{b}$} \\
\hline $\mathrm{CD}_{4} 5^{-}$ & $6.4(0.1-49.5)$ & $3.5(0.1-7.1)$ & $4.6(0.1-7.1)$ & 0.6081 \\
\hline $\mathrm{CD} 45^{\mathrm{dim}}$ & $0(0-10.5)$ & $5.2(0.1-45.7)$ & $3.7(0-45.7)$ & $<0.0001^{\mathrm{d}}$ \\
\hline $\mathrm{CD}_{133^{+}}$ & $5.2(1.1-31.2)$ & $7.1(0.2-69)$ & $6.8(0.2-69)$ & 0.3056 \\
\hline $\mathrm{CD}_{3} 4^{+}$ & $4.2(0.2-37.1)$ & $7.7(0.1-52.7)$ & $6.1(0.1-52.7)$ & 0.0920 \\
\hline $\mathrm{CD} 0^{+}$ & $3.9(0-13)$ & $0.6(0-12)$ & $0.1(0-13)$ & $0.0485^{c}$ \\
\hline \multicolumn{5}{|c|}{ The proportion of patients and semiquantitative values of anti-SARS-CoV-2 antibodies related to severity (S1 subunit of SARS-CoV-2 spike protein) } \\
\hline Humoral factor & Severe cases & Moderate cases & Total evaluated & $p$-value \\
\hline \multicolumn{5}{|c|}{ 'Patients' anti-SARS-CoV2 antibodies, n (\%) } \\
\hline Total class antibodies & $13(100)$ & $47(94.0)$ & $60(95.2)$ & 0.36 \\
\hline $\operatorname{lgG}$ class & $11(84.3)$ & $24(48.0)$ & $35(55.5)$ & $0.018^{\mathrm{c}}$ \\
\hline Optical density (OD) median value ${ }^{b}$ & $(n=13)$ & $(n=50)$ & $(n=63)$ & \\
\hline Total class antibodies & 102.0 & 16.45 & 28.4 & $0.007^{d}$ \\
\hline lgG class & 6.920 & 1.60 & 1.27 & $0.005^{d}$ \\
\hline
\end{tabular}

The concentration of platelet-derived growth factors in 20 selected COVID-19 patient samples of peripheral blood non-hematopoietic enriched stem cells cocktail (PB-NHESC-C)

\section{Platelet growth factor name (abbreviation)}

Stem Cell Factor (SCF)

Platelet Derived Growth Factor-AA (PDGF-AA)

Granulocyte-Colony Stimulation Factor (G-CSF)

Hepatocyte Growth Factor (HGF)

Epidermal Growth Factor (EGF)

Granulocyte Macrophage-Colony Stimulation Factor (GM-CSF)

T-Cell Growth Factor alpha (TGF-a)

Platelet Derived Growth Factor-BB (PDGF-BB)

Macrophage-Colony Stimulation Factor (M-CSF)

Angiopoietin-2 (Ang-2)

Fibroblast Growth Factor (FGF-basic)

Vascular Endothelial Growth Factor (VEGF)

Erythropoietin (EPO)
Total evaluated ( $\boldsymbol{n}$
[median (range)]
$4.26(4.26-21.51)$
$4.26(4.26-21.51)$
$382.3(148.8-2542)$
$18.28(18.28-97.25)$
$25.91(19.53-2885)$
$44.02(4.40-125.2)$
$8.99(8.99-17.97)$
$1.61(9.53-188.68)$
$51.09(16.04-187.2)$
$152(73.69-268.8)$
$35.51(2.56-327.4)$
$1.6(1.66-39.29)$
$1.7(8.72-91.96)$
$7.63(14.46-65.55)$

${ }^{a}: X^{2}$-test; ${ }^{b}:$ Mann-Whitney test for non-parametric samples; ${ }^{c}:$ significant difference; ${ }^{d}$ : highly significant difference; pg: picograms

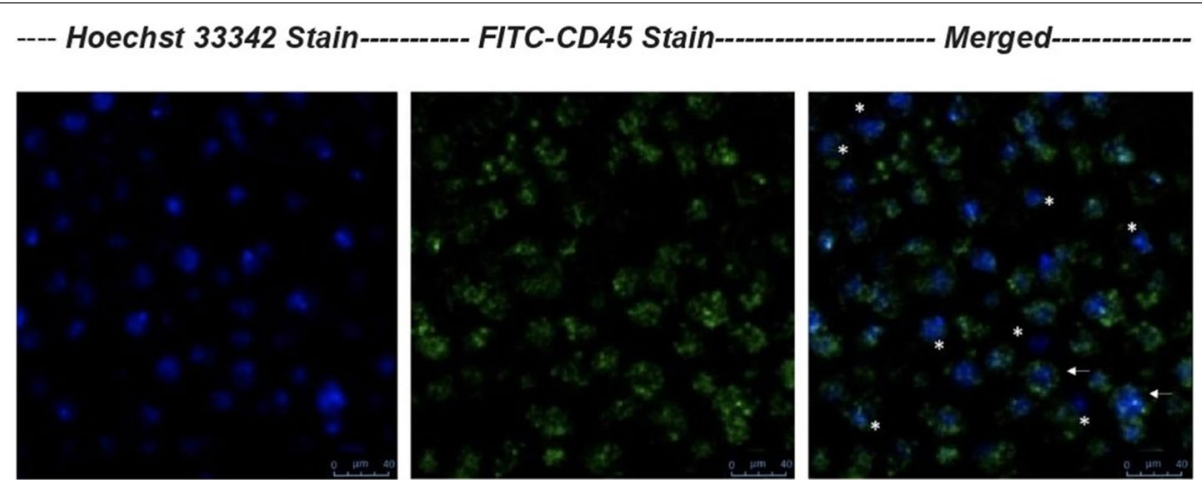

Fig. 3 Representative immunofluorescence images of PB-NHESC-C. Legend: Sample of the PB-NHESC-C were stained with FITC-conjugated monoclonal surface antibody CD45 (1:100) and Hoechst nucleic acid dye 33,342 (10 $\mathrm{\mu g} / \mathrm{ml})$. Images were acquired using a Leica SP8 confocal microscope using a 63x objective. Two main subpopulations were identified: the Non-hematopoietic $\left(^{*}\right.$ ) and the Hematopoietic Stem Cells (arrow) 
Table 3 Adverse events reported during the follow-up: SENTAD-COVID Study

\begin{tabular}{|c|c|c|c|c|}
\hline \multicolumn{2}{|l|}{ Adverse events } & $\begin{array}{l}\text { PB-NHESC-C + standard } \\
\text { care } \\
(n=69)\end{array}$ & Standard care $(n=70)$ & $p$-Value \\
\hline \multicolumn{2}{|c|}{ Total patients affected by adverse events, n (\%) } & $50(72.46)$ & $51(72.85)$ & $0.9590^{\mathrm{a}}$ \\
\hline \multicolumn{2}{|l|}{ Total adverse events, n (\%) } & $n=240$ & & \\
\hline \multicolumn{2}{|l|}{ Adverse events by group, n (\%) } & $107(44.58)$ & $133(55.41)$ & $0.8206^{b}$ \\
\hline \multicolumn{2}{|c|}{ Number of serious adverse events by group (including deaths) } & $35(32.71)$ & $57(42.85)$ & $0.1040^{\mathrm{a}}$ \\
\hline Adverse event type & Description & & & \\
\hline Total deaths, n (\%) & Death & $4(5.79)$ & $7(10)$ & $0.5319^{c}$ \\
\hline \multicolumn{5}{|l|}{ Other serious adverse events, n (\%) } \\
\hline Severe anemia & Hemoglobin reduction $<100 \mathrm{~g} / \mathrm{dL}$ & $10(14.49)$ & $8(11.42)$ & $0.5912^{a}$ \\
\hline Disease progression & Any score increased & $5(7.24)$ & $9(12.85)$ & $0.3989^{c}$ \\
\hline Sepsis & $\begin{array}{l}\text { Isolation of pathological fungal or } \\
\text { bacterial from blood cultures indicating } \\
\text { disseminated infections }\end{array}$ & $5(7.24)$ & $15(21.42)$ & $0.0278^{* c}$ \\
\hline Acute renal failure & Hemodialysis of at least 2 days & $4(5.79)$ & $6(8.57)$ & $0.7447^{c}$ \\
\hline Hypoxia & Oxygen saturation $\left(\mathrm{SpO}_{2}\right)<88 \%$ & $3(4.34)$ & $4(5.71)$ & $0.7184^{c}$ \\
\hline Acute respiratory distress syndrome & $\begin{array}{l}\text { Respiratory rate }>20 \text { or } \\
<12+\mathrm{SpO}_{2} \leq 88 \%+\text { score } \geq 6\end{array}$ & $3(4.34)$ & $5(7.14)$ & $0.7184^{c}$ \\
\hline Multiorgan failure & Score changed to 7 & $1(1.44)$ & $3(4.28)$ & $0.6195^{c}$ \\
\hline \multicolumn{5}{|l|}{ Other nonserious adverse events } \\
\hline Increased respiratory breath rate & $\mathrm{O}_{2}$ saturation levels $\geq 100$ & $30(43.47)$ & $34(48.57)$ & $0.7348^{\mathrm{a}}$ \\
\hline Hypertension & Blood pressure $\geq 120 / 80 \mathrm{mmHg}$ & $17(24.63)$ & $12(17.14)$ & $0.2789^{\mathrm{a}}$ \\
\hline Fever & Temperature $\geq 38^{\circ} \mathrm{C}$ & $13(18.84)$ & $14(20)$ & $0.8633^{\mathrm{a}}$ \\
\hline $\begin{array}{l}\text { Severe decreased absolute lymphocyte } \\
\text { count }\end{array}$ & Lymphocytes $<0.8 \times 10^{9} / \mathrm{L}$ & $8(11.59)$ & $9(12.85)$ & $1.0000^{\mathrm{a}}$ \\
\hline Sinus tachycardia & Heart rate $($ beats/min) $\geq 100$ & $2(2.89)$ & $3(4.28)$ & $1.0000^{c}$ \\
\hline Sinus bradycardia & Heart rate (beats/min) <60 & $1(1.45)$ & $2(2.85)$ & $1.0000^{c}$ \\
\hline Hypotension & Blood pressure $<100 / 60 \mathrm{mmHg}$ & $1(1.45)$ & $2(2.85)$ & $1.0000^{c}$ \\
\hline
\end{tabular}

PB-NHESC-C: peripheral blood non-hematopoietic enriched stem cell cocktail, ${ }^{\mathrm{a}}: \mathrm{x}^{2}$ - test; ${ }^{\mathrm{b}}:$ exact Poisson method; ${ }^{\mathrm{c}}$ : Fisher's exact test; ${ }^{*}:$ significant difference

a significant difference in slopes, indicating better results for the stem cell-treated patients $(p=0.0074)$ during the first 15 days of the follow-up.

\section{Clinical impact: the PB-NHESC-C-treated group exhibited a greater proportion of patients with clinical improvements} A higher proportion of patients with clinical improvement was found in the PB-NHESC-C treated group than in the control group by assessing nine parameters at day 10 of treatment, as shown in Fig. 5. Statistical significance was seen for the proportions of clinical improvements in at least two scores between them $(42.0 \%$ vs. $17.1 \%, \mathrm{RR}=0.85, p=0.002)$, respectively. Furthermore, the $R R R=31 \%$ is another statistical fact demonstrated for this result. Therefore, if we were applying this type of stem cells therapy to the control group, the number of patients with this clinical improvement increased by $31 \%$. The NNT showed a need to treat four patients with stem cells cocktail by nebulization to have one patient improvement in at least two scores in the first 9 days. Based on laboratory results, three other parameters also showed a statistically significant difference between both group: the appearance of lymphopenia (null vs. $26.3 \%$, $\mathrm{RR}=0.03 ; p=0.012$ ), the persistence of high levels of CRP (36.0\% vs. $76.2 \%, \mathrm{RR}=0.47 ; p=0.011$ ), and of the D-dimer (47.1\% vs. $92.3 \%, \mathrm{RR}=0.51 ; p=0.010)$. All are considered indicators of COVID severity.

\section{Exploratory endpoints: lymphocyte, neutrophils and acute phase reactant changes in PB-NHESC-C-treated patients}

Table 4 shows the comparison of laboratory results before and after in each group of patients and the comparison between these groups after 28 days of follow-up.

After treatment with PB-NHESC-C, all COVID-19 patients showed better results in normalizing the absolute number of lymphocytes and improving the neutrophil/lymphocyte ratio compared with the control group. In addition, fibrinogen, IL-6, and C-reactive protein levels also significantly decreased in the treated group during the follow-up. In the control group, only statistically significant changes were observed in the reduction of $\mathrm{C}$-reactive protein levels. Comparing blood cell counts 


\section{A) Severe COVID-19 patients}

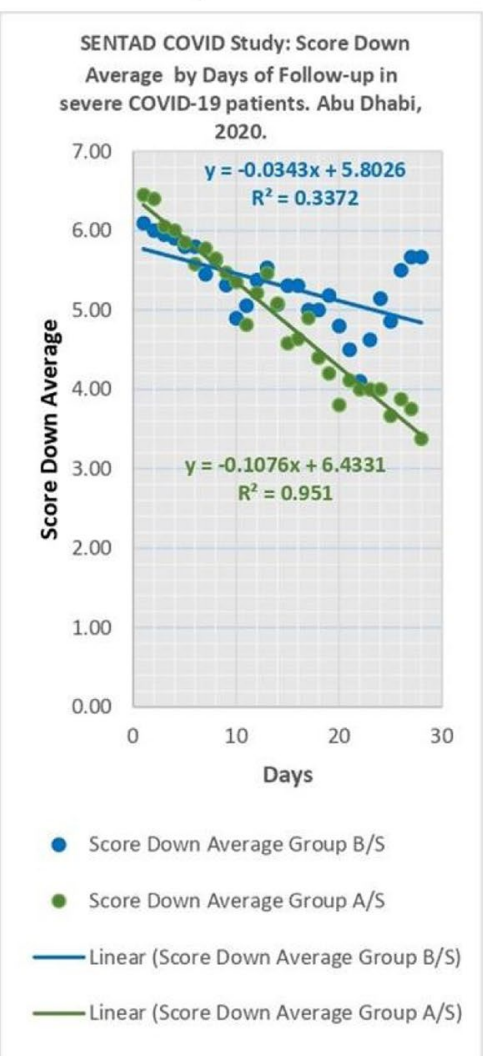

\section{B) Moderate COVID-19 patients}

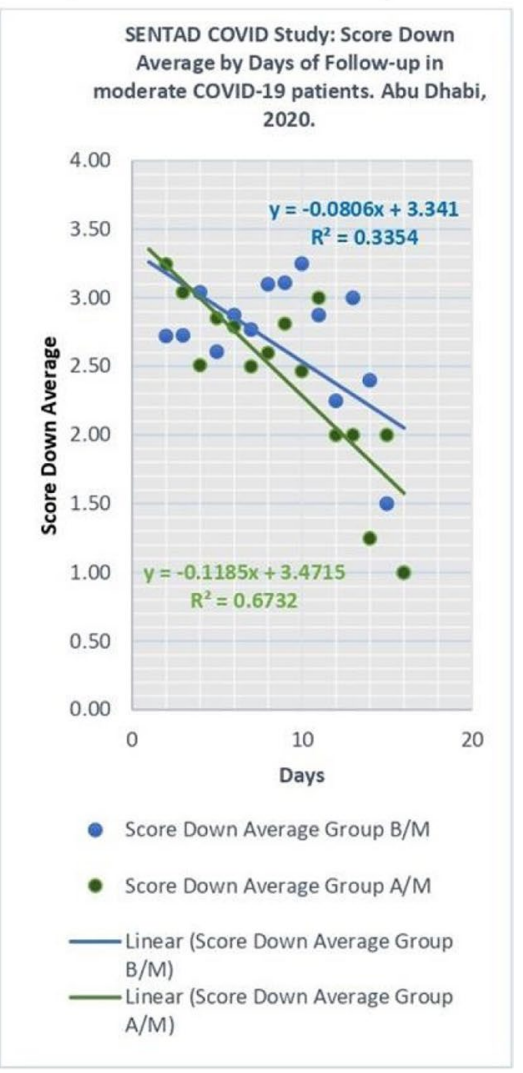

Fig. 4 Clinical improvement. Different trend line slopes during the clinical trial follow-up. Legend: Group A/S: Peripheral Blood Non-Hematopoietic Enriched Stem Cell Cocktail (PB- NHESC-C) Treated classified as severe; Group B/S: Controls classified as severe; Group A/M: PB-NHESC-C Treated classified as moderate; Group B/M: Controls classified as moderate

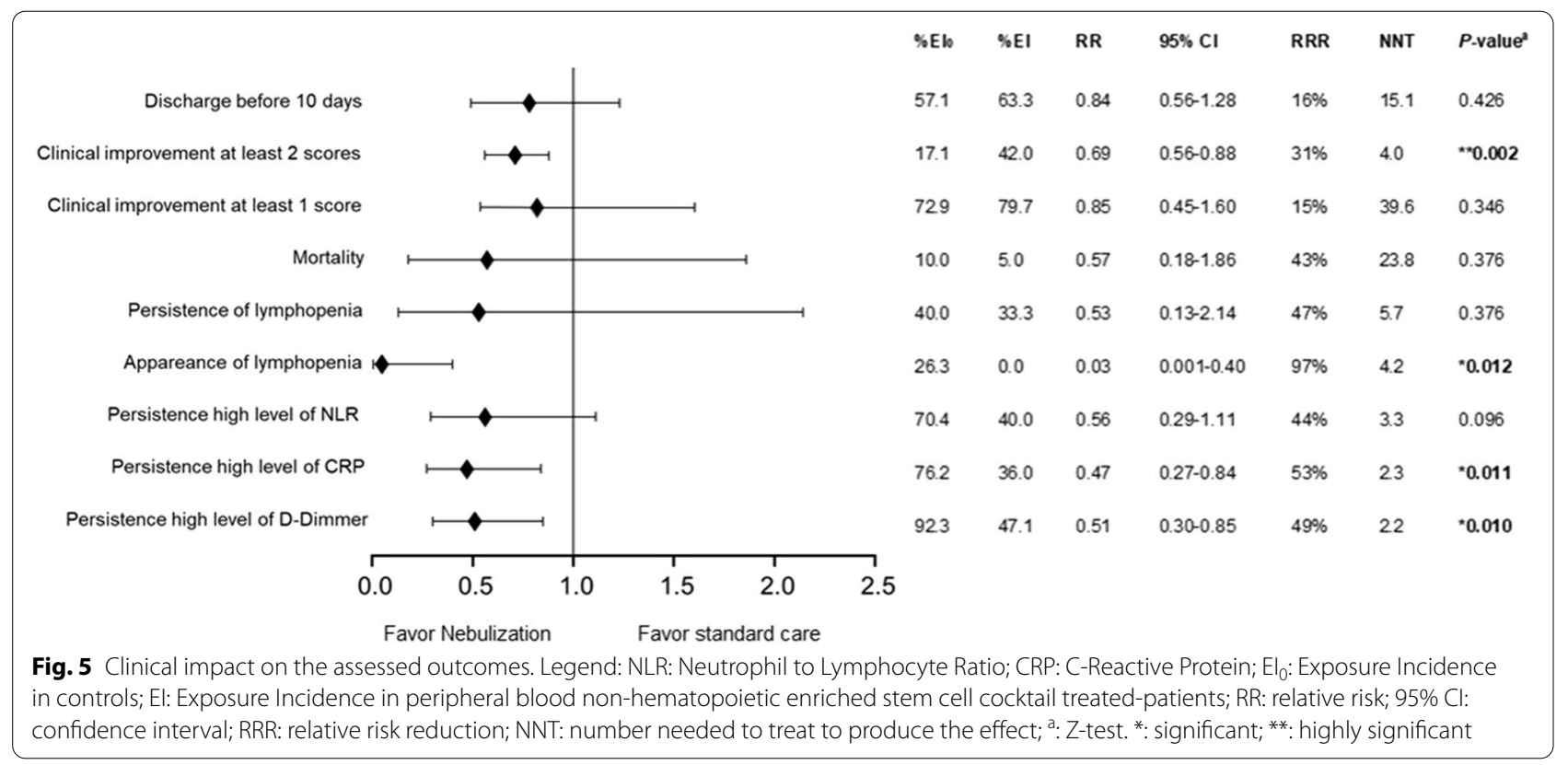


Table 4 The laboratory follow-up of COVID-19 Patients During the Monitoring Period. Abu Dhabi, 2020

\begin{tabular}{|c|c|c|c|c|c|c|c|c|}
\hline \multirow[t]{2}{*}{ Variables } & \multicolumn{4}{|c|}{ PB-NHESC-C treated } & \multicolumn{3}{|c|}{ Control } & \multirow[t]{2}{*}{$p$-value ${ }^{b}$} \\
\hline & Time & $\mathrm{n}$ & Median (95\% Cl) & $p$-value ${ }^{a}$ & $\mathbf{n}$ & Median $(95 \% \mathrm{Cl})$ & $p$-value ${ }^{a}$ & \\
\hline \multirow[t]{2}{*}{ White blood cells $\left(10^{9} / \mathrm{L}\right)$} & $1 \mathrm{st}$ & 51 & $6.8(4,20.45)$ & 0.5377 & 35 & $6.855(3.199,13.45)$ & 0.0753 & $0.0174^{*}$ \\
\hline & 2nd & & $7.6(3.84,18.76)$ & & & $10.99(4.006,24.5)$ & & \\
\hline \multirow[t]{2}{*}{ Neutrophils $\left(10^{9} / \mathrm{L}\right)$} & $1 s t$ & 51 & $4.4(1.6,17.75)$ & 0.2251 & 35 & $4.49(1.812,12)$ & 0.3023 & $0.0029^{* *}$ \\
\hline & 2nd & & $4.3(1.5,15.18)$ & & & $7.27(2.21,22.65)$ & & \\
\hline \multirow[t]{2}{*}{ Lymphocytes $\left(10^{9} / \mathrm{L}\right)$} & $1 \mathrm{st}$ & 51 & $1.305(0.55,3.2)$ & $<0.0001^{* * *}$ & 35 & $1.305(0.5205,3.46)$ & 0.068 & $0.0017^{* *}$ \\
\hline & 2nd & & $2.1(0.802,3.38)$ & & & $1.64(0.38,2.758)$ & & \\
\hline \multirow[t]{2}{*}{ Monocytes $\left(10^{9} / L\right)$} & $1 s t$ & 51 & $0.6(0.3,1.25)$ & 0.9838 & 35 & $0.535(0.1355,1.078)$ & $0.0017^{* *}$ & $0.019^{*}$ \\
\hline & 2nd & & $0.6(0.3,1.504)$ & & & $0.88(0.302,1.852)$ & & \\
\hline \multirow[t]{2}{*}{ Eosinophils $\left(10^{9} / \mathrm{L}\right)$} & $1 \mathrm{st}$ & 51 & $0.1(0,0.3)$ & $<0.0001^{* * *}$ & 35 & $0.075(0.00,0.4155)$ & $0.0074^{* *}$ & 0.3378 \\
\hline & 2nd & & $0.2(0,0.82)$ & & & $0.18(0.00,0.81)$ & & \\
\hline \multirow[t]{2}{*}{ Basophils $\left(10^{9} / \mathrm{L}\right)$} & $1 s t$ & 51 & $0.0(0,0.1)$ & $<0.0001^{* * *}$ & 35 & $0.02(0.00,0.0645)$ & $0.0109 *$ & 0.3925 \\
\hline & 2nd & & $0.1(0,0.2)$ & & & $0.03(0.00,0.158)$ & & \\
\hline \multirow[t]{2}{*}{$N L R(U)$} & $1 s t$ & 51 & $3(0.86,15.66)$ & $0.0011^{* *}$ & 35 & $2.6(0.84,15.7)$ & 0.5764 & $<0.0001^{* * *}$ \\
\hline & 2nd & & $1.8(0.56,16.79)$ & & & $4.3(1.1,57.66)$ & & \\
\hline \multirow[t]{2}{*}{ D-Dimer ( $\mu \mathrm{g} \mathrm{FEU/mL)}$} & $1 s t$ & 49 & $0.4(0.2,8.1)$ & 0.1113 & 31 & $0.57(0.21,14.8)$ & 0.3931 & $<0.0001^{* * *}$ \\
\hline & 2nd & & $0.2(0,3.6)$ & & & $1.51(0.26,537.7)$ & & \\
\hline \multirow[t]{2}{*}{ Fibrinogen (g/dL) } & $1 \mathrm{st}$ & 31 & $718(380,1136)$ & $<0.0001^{* * *}$ & 13 & $420(240,1940)$ & 0.0625 & $<0.0001^{* * *}$ \\
\hline & 2nd & & $350(220,69)$ & & & $470(390,980)$ & & \\
\hline \multirow[t]{2}{*}{ IL-6 (pg/mL) } & $1 s t$ & 31 & $20.3(1.5,3361)$ & $<0.0001^{* * *}$ & 0 & ND & ND & ND \\
\hline & 2nd & & $3.05(1.4,3384)$ & & & ND & & \\
\hline \multirow[t]{2}{*}{ C-reactive protein (mg/L) } & $1 s t$ & 31 & $34(0.6,381.8)$ & $<0.0001^{* * *}$ & 24 & $21.79(0.4,335.3)$ & $0.0049^{* *}$ & $0.0048^{* *}$ \\
\hline & 2nd & & $3.6(0.42,111)$ & & & $16.45(0.6,350)$ & & \\
\hline
\end{tabular}

Time: comparing 1st and 2nd studies inside each group; n: sample size; NLR: neutrophil/lymphocyte ratio; ND: not determined; $95 \%$ Cl: Confidence interval; ${ }^{\text {a: }}$ Wilcoxon test for nonparametric pair samples; ${ }^{b}$ : Mann-Whitney U test, comparing the two groups; *: significant difference; **: higly significant; ***: very higly significant

in both groups, differences were observed in the levels of absolute white blood cells, absolute lymphocytes, neutrophils, monocytes, the neutrophils/lymphocyte ratio, and acute phase reactants, such as D-dimer, fibrinogen, and $\mathrm{C}$-reactive protein, because the changes in the controls were not as notable as those in the PB-NHESC-C-treated patients.

\section{High-resolution computer tomography scans (CT) images of a Patient's chest}

The evaluated CT corresponds to 37 patients from group A and three from group B. Nevertheless, Fig. 6 shown representative $\mathrm{CT}$ images of one group PB-NFESC$\mathrm{C}$ treated COVID severe patient with a score of 4 as an example of his fast recovery.

On the day of recruitment, patient No. 4 CT chest images showed patchy consolidations in the bilateral lower lobes and right middle lobe as well as few peripheral consolidations in the left upper lobe and patchy peripheral ground-glass opacities in the upper lobes. An important change in improvement was noted after 4 days of nebulization.

\section{Discussion}

The clinical data of recruited patients at the time of inclusion included all signs and symptoms that were more frequently noted in COVID-19 patients, including fever, weakness, shortness of breath, secondary bacterial sepsis, and lower oxygen saturation [25].

The loss of patients during the follow-up was the main limitation for collecting data because many of the patients in the first and second tertiles recovered and were released from hospitals, rendering some statistical limitations and bias in this study.

In addition, the quantities of each allocation group changed daily, so data monitoring was performed to evaluate clinical improvements and adverse events, including deaths. However, a proper quantitative meta-analysis, with a larger sample could be designed to validate this study and better assess the effect of treatment.

The randomization yielded 69 patients for Group A and 70 for Group B. Age, gender, nationalities, and other demographic and clinical information obtained at the time of recruitment were similar between both groups, and the only significant difference was found in a portion of body mass index (BMI) categories, such 


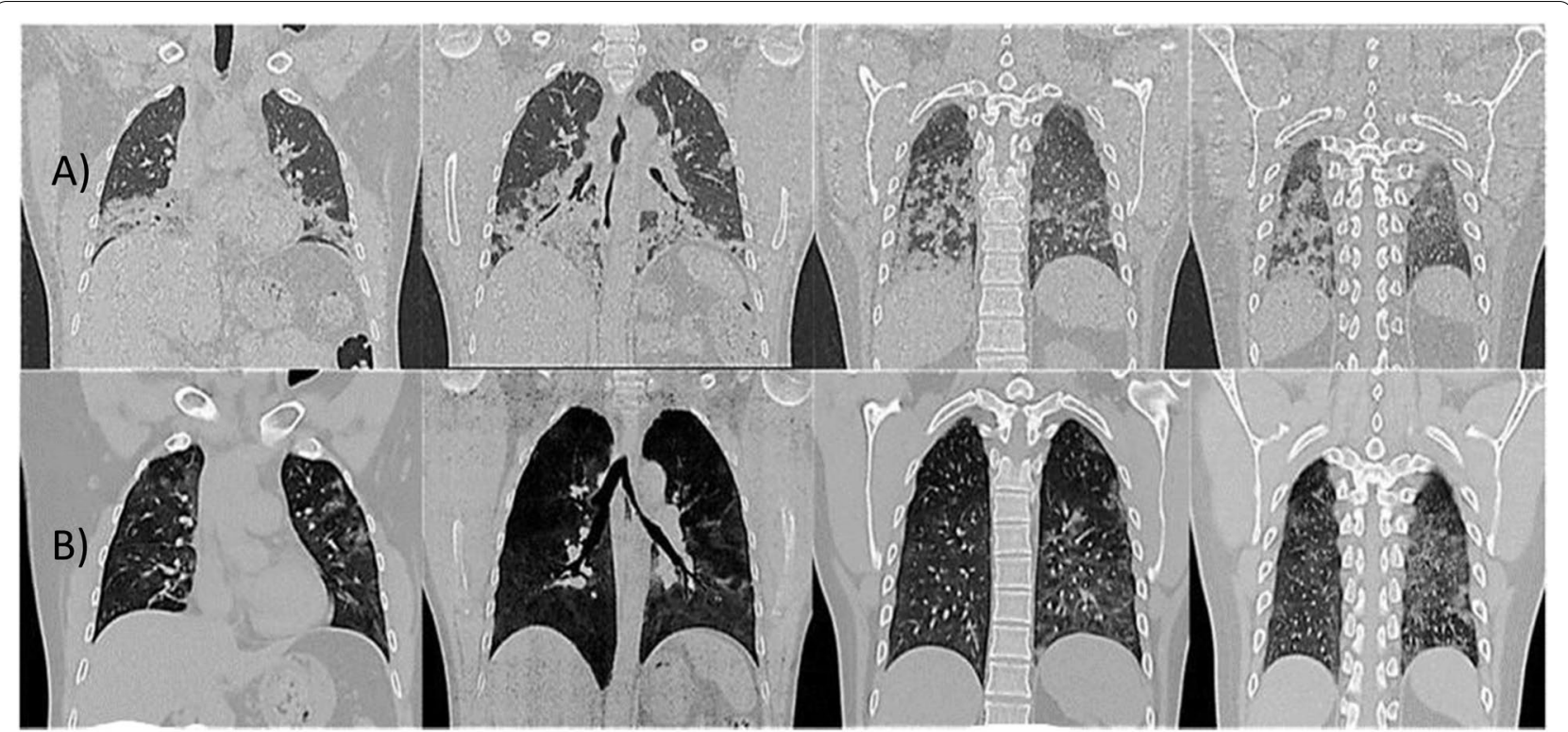

Fig. 6 High-Resolution Computer Tomography Scans Images of a Patient's Chest. Legend: Patient No. 4. Group A (peripheral blood non-hematopoietic enriched stem cell cocktail + standard care): Images a) Day of recruitment (April 1st). Images b) Four days after the first dose of stem cell treatment (April 13th, nebulization was initiated on April 9th, and the second dose was commenced on April 10th)

as normal weight and overweight. For both of these factors, the control group exhibited better values. A smaller number of patients with these disadvantages were included by chance in the stem cell-treated group and some reports have noted a poor prognosis for overweight patients [26].The short number of female patients in the trial may be related to the economically active resident population in UAE, characterized by expatriate young male workers, most of them living in only-male facility residences without their family in this country. Patients in the trial represent 15 nationalities, which is similar to that noted in the UAE population, giving strong meaning to the study.

This work describes the characterization of a cocktail of autologous stem cells suspended in PDGF that also includes anti-SARS-CoV-2 antibodies. These cells express markers CD133 and CD34, known as pluripotent markers, and to a lesser extent CD90; the cocktail has a similar number of circulating endothelial cells to that reported in response to endothelial damage and dysfunction in many diseases [27]. The $\mathrm{CD} 45^{-}$cell fraction is similar in size and phenotype to that described for VSELs, but further studies will be needed for better cell characterization [28]. Given that PB-NHESC-C is a product obtained from COVID-19 patients, the phenotypes cellular number and variability is influenced by the immune response to viral infection and the mobilization of progenitor cells to damaged tissue. Therefore, these differences explain what we found in this study between the severe and moderate groups [29]. Indeed, the significant CD5 ${ }^{\text {dim }}$ cell count in the cellular preparation of moderate cases is synergically correlated with the absolute count of lymphocytes in peripheral blood, indicating their potential role as lymphocyte precursors. The increase in $\mathrm{CD} 45^{-}$and $\mathrm{CD} 90^{+}$ cell counts found in the PB-NHESC-C of severe patients could be representing an increase in a VSELs mobilization under stress conditions in response to the release of inflammatory cytokines, which is known as one of the red flags of the disease [30].

The effects of stem cell therapy are dose dependent. The efficacy of the stem cell cocktail product should be evaluated based on the presence, phenotype, and function of different cellular subsets. Nevertheless, in this work we didn't find a relationship between the total dose of stem cells administered and the product's efficacy. Besides, our results were more correlated with specific stem cell subsets. Indeed, hospital discharge before 10 days was related to the number of $\mathrm{CD} 45^{\mathrm{dim}}$ cells and, more specifically, CD $45^{\mathrm{dim}} / \mathrm{CD} 34^{+}$cells.

Furthermore, in spite of the well-known role of CD34 ${ }^{+}$ hematopoietic stem cells in hematopoietic transplantation [31], their therapeutic role in pulmonary diseases has not been widely studied. A few supportive studies have reported their increase in PB during interstitial lung disease as a compensatory mechanism of tissue repair [32] and their ability to differentiate into other cell lineages, including epithelial cells [33]. CD34 is expressed in a wide range of cells in addition to hematopoietic cells 
and stromal, epithelial, and endothelial cells. The function of this marker has not been fully clarified, but it is associated with the inhibition or facilitation of adhesion, proliferation, and regulation of cell differentiation [34]. A significant increase in the $\mathrm{PB}$ of $\mathrm{CD} 45^{\mathrm{dim}} / \mathrm{CD} 34^{+}$cells in severe COVID ${ }^{-} 19$ patients was reported [29] and interpreted as a response to endothelial regeneration during hypoxia. No relationship was found between the number of $\mathrm{CD}_{34}{ }^{+}$cells in PB-NHESC-C and disease severity in our study. These contradictory findings may be due to differences in study populations, methodology, and parameter analysis.

Furthermore, we found that nebulization of a high dose of $\mathrm{CD} 0^{+}$cells was associated with a longer hospital stay, and $\mathrm{CD} 90^{+}$cells were more highly expressed in PB-NHESC-C cells of severe patients who required a longer hospital stay. This finding was not expected given the immunosuppressive activity of CD90 that controls inflammation. We attributed the alteration of CD90 activity to the high expression of proinflammatory cytokines, such as IL- $1 \beta$ and TNF $\alpha$, which are commonly increased in COVID-19 patients [35].

On the other hand, it is well known that ACE2 is expressed in most human cells, and SARS-CoV-2 enters the host cell via binding of the $S$ protein on the viral surface to ACE2 on the cell surface [36]. In addition to the lung, ACE2 is widely expressed in human tissues, including the heart, liver, kidney, and digestive organs [37]. Almost all endothelial cells and smooth muscle cells in organs express ACE2; therefore, we measured ACE2 expression in our investigational product. A recent study demonstrated that ACE2 and the entry-facilitating transmembrane protease TMPRSS2 are expressed on VSELs, and it is hypothesized that the interaction of its receptor activates the Nlrp3 inflammasome. Thus, hyperactivation of these cells can promote the death of infected cells by pyroptosis [38]. Nevertheless, there was no evidence of the loss of viability in the stem cell cocktail in this trial, and SARS-CoV-2 did not damage the cells. If the cells were destroyed, the PB-NHESC-C cocktail would not demonstrate efficacy in controlling the patient's cytokine storm.

Positivity for anti-SARS-CoV-2 IgG antibodies and the semiquantitative estimation of anti-SARS-CoV-2 T/G did not show beneficial effects on endpoints. Antibody nebulization of human plasma does not cause loss of immunoglobulin function in animal models [39] and is well tolerated for human treatment [40]. Nevertheless, the exclusive presence of anti-SARS-CoV-2 IgG antibodies in the nebulized product evaluated in this study also potentially influenced the effectiveness of PB-NHESC-C therapy despite not being related to antibody concentration. This notion should be clarified in other studies, and these results could be influenced because the concentration of anti-SARS-CoV-2 antibodies was significantly higher in the group of severe patients who require a longer hospital stay due to disease severity.

Additionally, we evaluated the presence of human growth factor in PDGF, which was used as an excipient of the stem cell cocktail, among a small number of cases with the purpose of better characterizing the final investigational product. Notably, it was not possible to relate these factors with efficacy. In previous communications, similar profiles of angiogenesis and endothelial damage markers in the peripheral blood of patients were obtained in noncritical and critical phases of COVID-19 [41]. Higher concentrations of factors, such as PDGF-AA and M-SCF, play an essential role in many processes related to the immune response, angiogenesis, and tissue repair [42]. A potential role of PDGF and its contribution to the efficacy of the treatment was not addressed in this study and is currently under further investigation.

Death, sepsis, disease progression, acute renal failure, hypoxia, acute respiratory distress syndrome, and multiorgan failure are serious adverse events [41]. However, their frequencies were lower in group A than in group B. Only the increased sepsis frequency found in the control group was significantly different between the two groups. It is known that SARS-CoV-2 infection predisposes people to have bacterial and fungal sepsis complications or even a septic shock. In addition, it is associated with high mortality of severe COVID-19 patients. Therefore, this difference can be assumed as a protective effect of the investigational product not observed in the control group. Severe anemia, an expected adverse event after blood collection for the PB-NHESC-C preparation, was similar in both groups, indicating a correlation with SARS-CoV-2 infection and not with the treatment because anemia has also been reported a COVID-19 complication $[43,44]$. None of the considered nonserious events assessed, such as increased respiratory breath rate, hypertension, fever, decreased absolute lymphocyte count, tachycardia, bradycardia, and hypotension, showed significant differences between the groups. In addition, administration-related or acute allergic reactions were not observed within $2 \mathrm{~h}$ to 3 days after nebulization. Therefore, the use of PB-NHESC-C didn't lead to delayed hypersensitivity or secondary infections in 28 days of follow-up.

The clinical improvement observed in severe and moderate COVID-19 patients during the follow-up supported the potential application of stem cell cocktails. The trend line slope in both patients treated with stem cells showed a better adjustment to the right line and less dispersion to the center compared with patients treated with the standard of care, indicating that PB-NHESC-C 
facilitates accelerated clinical improvement that portend an improved recovery prognosis compared with those treated with standard care alone. However, no relationship was found between a reduction of 2 or more points on the disease severity scale and the dose of nebulized cells, cell phenotypes, or positivity for anti-SARS-CoV2, total and IgG antibodies.

Some reports also found the appearance of lymphopenia as well as high levels of $\mathrm{D}$-dimer and C-reactive protein in COVID-19 patients [45, 46]. In general, the elevation of $\mathrm{D}$-dimer levels is not a specific response and is most commonly used in the diagnosis of venous thromboembolism, pulmonary embolism, and acute abdomen disorders $[47,48]$. C-reactive protein is a biomarker with high sensitivity for inflammation. It is part of the host response to the production of cytokines, particularly TNF $\alpha$, IL-6, MCP1, and IL-8, which are secreted by several immune cells, including $\mathrm{T}$ cells. An increased C-reactive protein levels are also indicative of a myocardial effect [49].

Therapy with compressor-nebulized PB-NHESC$\mathrm{C}$ modifies the immune response as demonstrated by statistically significant changes in acute phase serum markers and coagulation tests, such as D-dimer, after treatment in COVID-19 patients. As found in this study, the levels of some acute phase reactants in COVID-19 patients were higher than the normal range at the start of stem cell therapy. Hence, the cytokine release syndrome caused by abnormally activated immune cells resulted in deterioration of the patient's condition, which may alter endothelial cell function, induce capillary leakage, promote mucus blockage in the lung and induce respiratory failure. These effects could even cause an inflammatory cytokine storm leading to multiple organ failure. However, this effect was reverted in most patients when their levels of inflammatory reactants were normalized after treatment with PB-NHESC-C.

Various chest imaging features have been reported in COVID-19, and the images are similar to those found in other types of coronavirus syndromes. However, in this study, the CT chest image provides an example of a patient who rapidly improved after investigational product treatment.

PB-NHESC-C cocktail therapy may inhibit the overactivation of the immune system and significantly improve inflammation even in severe COVID-19 patients. The majority of patients with severe COVID19 pneumonia survive and recover. The nebulization of PB-NHESC-C improved the outcome of COVID-19 patients may be due to regulation of the inflammatory response and the promotion of tissue repair and regeneration. However, a statistically significant difference in the percentage of patients discharged from the hospital was not noted. After day 9, the value was higher in the PBNHESC-C treated group compared with controls with a clinical impact of $\mathrm{RR}=0.84$.

Additionally, the proportion of patients with an improved NLR in the stem cell-treated group was greater than that in the controls. Both clinical impact factors favored nebulization, as NLR levels have been a predictive marker for severity and mortality in COVID-19 [50]. More improvements measured by at least a 2-point reduction on the disease severity scale were noted in the treated group with a highly statistically significant difference. In contrast, more improvements measured a 1-point drop were pointed out in the treated group, but these results were not significant. However, it should be noted that treatment does not yield equivalent or inferior effects. Increasing the size of the sample could lead to better statistically significant differences in results.

The cure for COVID-19 is essentially dependent on the patient's immune system. When the over-activated immune system kills the virus, it produces many inflammatory factors, leading to severe cytokine storms, and older patients may be more easily affected due to immunosenescence [51]. Cells, such as mesenchymal stem cells, have been tested to treat lung diseases using nebulization and aerosols [52, 53]. In cases of COVID-19, other cellular therapy products using different types of stem cells have also aided patient's recovery [13, 54-56].

\section{Conclusions}

This paper is the first report of an autologous treatment with minimally manipulated stem cells. The main component of the cocktail is non-hematopoietic cells, which were obtained using a simplified autologous cell isolation procedure that can be implemented in blood banks or transfusion center facilities. The PB-NHESC-C was safe and improved the clinical and laboratory outcomes in most treated patients with the potential to reduce hospitalization and mortality.

\footnotetext{
Abbreviations

AAD: Amino-actinomycin D; ACE2: Angiotensin-converting enzyme 2; ADSCC: Abu Dhabi Stem Cells Center; Ang-2: Angiopoietin-2; APC: Allophycocyanin; ARDS: Acute Respiratory Distress Syndrome; CTCAE: Common Terminology Criteria for Adverse Events; COVID-19: Coronavirus disease 2019; CoV2T: SARS-CoV2 total antibodies; CoV2G: SARS-CoV2 IgG antibodies; Cl: Confidence interval; CT: Computerized tomography scans; EGF: Epidermal growth factor; EPO: Erythropoietin; FGF: Fibroblast growth factor; FICT: Fluorescein isothiocyanate; G-CSF: Granulocyte-colony stimulation factor; GM-CSF: Granulocyte/ macrophage-colony stimulation factor; HSCs: Hematopoietic stem cells; HGF: Hepatocyte growth factor; HBV: Hepatitis B virus; HIV: Human immunodeficiency virus; iPSCs: Induced pluripotent stem cells; IRB: Institutional review board; M-CSF: Macrophage-colony stimulation factor; MSCs: Mesenchymal stem cells; NLR: Neutrophil to lymphocyte ratio; NNT: Number needed to be treated; PB: Peripheral blood; PB-NHESC-C: Peripheral blood-derived nonhematopoietic enriched stem cell cocktail; PDGF-AA: Platelet-derived growth
} 
factor AA; PDGF-BB: Platelet-derived growth factor BB; PDGF: Platelet-derived growth factors; PCP: Platelet-concentrated plasma; REC: Research Ethics Committee; RNA: Ribonucleic acid; RR: Relative risk; RRR: Relative risk reduction; RT: Room temperature; RT-PCR: Real-time Polymerase Chain Reaction; SARS-CoV-2: Severe Acute Respiratory Syndrome Coronavirus-2; SCF: Stem cell factor; $\mathrm{SpO}_{2}$ : Oxygen Saturation; TGF-a: T-cell growth factor-alpha; TMPRSS2: Transmembrane protease-serine 2; VSELs: Very small embryonic-like stem cells; VEGF: Vascular endothelial growth factor; WHO: World Health Organization.

\section{Acknowledgments}

This work was supported by different governmental entities of the United Arab Emirates as part of the national efforts to fight the COVID-19 pandemic. The authors are grateful to Informatics and all frontline healthcare workers from ADSCC and SEHA participating hospitals for their support and commitment to the quality of the information provided to the research team. We also would like to thank the Core Technology Platforms team at New York University Abu Dhabi for assisting with this work.

\section{Authors' contributions}

YVC: Leading conceptualization, funding acquisitions, project administration, also participate in resources, and writing-review and editing; FMA: Leading Resources, also participation in funding acquisition, project administration, and writing-review and editing; YMCA: Leading Methodology, also participate in conceptualization, resources, data curation, validation, visualization and writing-review and editing; CAW: Leading Writing-review and editing, also participate in methodology, investigation, formal analysis and visualization; YMA Resources, data curation, validation, and visualization; PS: Resources and data curation, AAA: Resources and investigation; AA: Resources, investigation and validation; GMTZ: Resources, data curation, investigation and writing-review and editing; MWM: Leading data curation, also participate in formal analysis, and writing-review and editing; DQS: Leading formal analysis, also participate in conceptualization, methodology, data curation, and writing-review and editing; LAH: Leading visualization, also participate in resources, investigation, validation, and writing-review and editing. AABH: Leading investigation and validation, also participate in conceptualization, methodology, formal analysis, visualization and writing-review and editing; RARJ: Writing original draft, conceptualization, data curation, validation, formal analysis, visualization, and writing-review and editing. The author(s) read and approved the final manuscript.

\section{Authors' information}

\section{Author's titles, email and ORCID ID:}

1. YVC, M.D. with Specialty in Immunology. email: yendry.ventura@adscc.ae. ORCID ID: https://orcid.org/0000-0002-5373-3414

2. FMA, M.D., Specialty in Haematology. M.Sc. in Oncology and Cancer Biology. email: fatimkaabi@seha.ae. ORCID ID: https://orcid.org/ 0000-0001-6646-5722.

3. YMCA, M.D. with Specialty in Immunology. email: yandy.castillo@adscc.ae. ORCID ID: https://orcid.org/0000-0001-8169-9914.

4. CAVV, M.D. with Specialty in Immunology, M.Sc. in Infectious Diseases, and M.Sc. in Medical Education. email: carlos.valverde@adscc.ae. ORCID ID: https:// orcid.org/0000-0001-7478-0482

5. YMA, M.D. with Specialty in Radiology, M.Sc. in Radiodiagnosis, M.Sc. in International Healthcare Leadership, email:yasmine.maher@adscc.ae ORCID ID: https://orcid.org/0000-0002-8918-0831.

6. PS, M.D. with Specialty in Orthopaedic Surgery, M.Sc. in Orthopaedic and Trauma Surgery. Email: p.sanna@adscc.ae ORCID ID: https:/orcid.org/ 0000-0002-7431-8471.

7. AAA, M.D. acting as Medical Resident in Haematology, email: ayealmarzo oqi@seha.ae ORCID ID: https://orcid.org/0000-0002-8234-4303.

8. AA, M.D. with Specialty in Clinical Pathology, M.Sc. in Clinical and Chemical Pathology, Ph.D., Clinical Pathology. Email: abeer.alsayed@adscc.ae ORCID ID: https://orcid.org/0000-0002-4718-9723

9. GMTZ, M.D., Consultant Urologist, Ph.D., Surgery. Email: gina.zambrano@ adscc.ae ORCID ID: https://orcid.org/0000-0001-6424-2621

10. MWM, M.D. with Specialty in Biomedical Statistics. email: m_wade@yahoo. com ORCID ID: https://orcid.org/0000-0001-5212-9840

11. DQS, M.Sc. in Mathematics and Physics, Ph.D., Physics. email: dquesada@ mdc.edu ORCID ID: https://orcid.org/0000-0001-8211-6485.

12. LAH, B.Sc. in Biochemistry, M.Sc. in Biochemistry, M.Sc. in Organic Chemistry, and Ph.D., Biochemistry. email: loubna.hadi@adscc.ae; ORCID ID: https:// orcid.org/0000-0002-5271-0798
13. AABH, B.Sc. in Biological Sciences, Ph.D., Health Science. email: antonio. bencomo@adscc.ae; ORCID ID: https://orcid.org/0000-0002-6209-0393.

14. RARJ, B.Sc. in Microbiology, M.Sc. in Immunology and Ph.D., Health Sciences. email: rene.rivero@adscc.ae ORCID ID: https://orcid.org/ 0000-0001-7222-727X.

Funding

This whole work was supported by the Abu Dhabi Stem Cells Center management, under Mr. Hamad Al Shamsi, as CEO and employer.

\section{Availability of data and materials}

Datasets used and/or analyzed during the current study are available from the corresponding author on reasonable request.

\section{Declarations}

\section{Ethics approval and consent to participate}

The clinical trial called "SENTAD- COVID Study" was designed by Abu Dhabi Stem Cells Center (ADSCC), according to the research project approved by the ADSCC Research Ethics Committee on April 4th, 2020, and later by a conditional exceptional approval letter by the Ministry of Health and Prevention of the UAE, via the Emirates Institutional Review Board (IRB) for COVID-19 Research Committee, on June, 25th 2020. The Helsinki Declaration was based on patients' informed consent and the ethical conduction of all participants.

\section{Consent for publication}

The PB-NHESC-C treated patient No. 4 gave a written consent to publish his $\mathrm{CT}$ chest images.

\section{Competing interests}

The procedure for obtaining the PB-NHESC-C mentioned in this report was advanced through research conducted and patented for ADSCC by YVC, $A A B H$, and FMA. We declare that YMCA, CAVV, PS, YMA, AA, LAH, GMTZ, and RARJ are also staff members of ADSCC. For the rest thereof the co-authors, there are no competing interests. In May 2020, the patented procedure was approved by the Ministry of Economy of the United Arab Emirates, and also in May 2020, 5 of the authors (FMA, YVC, RARJ, AABH, and YMCA) received 3 Copyrights from the INTEROCO Copyright Office (EC-01-002809, EC-01002810, and EC-01-002811), so this procedure including nebulization has been accredited to ADSCC. Nevertheless, YVC and the other patent authors resigned to be eligible to receive equity due to the licensing of this procedure.

\section{Author details}

${ }^{1}$ Abu Dhabi Stem Cells Center, Al Misahah Street, Villa No. 25, Rowdhat, Zone-1, POB 4600, Abu Dhabi City, United Arab Emirates. ${ }^{2}$ Sheikh Khalifa Medical City Hospital, POB 51900, Abu Dhabi City, United Arab Emirates. ${ }^{3}$ McHari International College, Nassau, Bahamas. ${ }^{4}$ Miami Dade College, Mathematics Department Chair, Wolfson Campus, Miami, FL 33132, USA.

Received: 24 May 2021 Accepted: 5 September 2021

Published online: 03 November 2021

\section{References}

1. Sohrabi C, Alsafi Z, O'Neill N, Khan M, Kerwan A, Al-Jabir A, et al. World Health Organization declares global emergency: a review of the 2019 novel coronavirus (COVID-19). Int J Surg. 2020;76:71-6.

2. WHO. COVID-19. United Arab Emirates situation. Statistics. Geneva: WHO; 2010

3. Tay MZ, Poh CM, Rénia L, MacAry PA, Ng LFP. The trinity of COVID19: immunity, inflammation and intervention. Nat Rev Immunol. 2020;20:363-74.

4. Tang D, Comish P, Kang R. The hallmarks of COVID-19 disease. PLoS Pathog. 2020;16:e1008536.

5. Clinical Trial Database. Athersys Clinical Trials Group. MultiStem administration for COVID-19 Induced ARDS (MACoVIA) (MACoVIA). https://clini caltrials.gov/ct2/show/NCT04367077. Accessed 17 June 2020.

6. Tashkin D. A review of nebulized drug delivery in COPD. Int J Chron Obstruct Pulmon Dis. 2016;11:2585-96. 
7. Shin DM, Liu R, Wu W, Waigel SJ, Zacharias W, Ratajczak MZ, et al. Global gene expression analysis of very small embryonic-like stem cells reveals that the Ezh2-dependent bivalent domain mechanism contributes to their pluripotent state. Stem Cells Dev. 2012;21:1639-52.

8. Gurusamy N, Alsayari A, Rajasingh S, Rajasingh J. Adult stem cells for regenerative therapy. Prog Mol Biol Transl Sci. 2018;160:1-22.

9. Golchin A, Farahany TZ. Biological products: cellular therapy and FDA approved products. Stem Cell Rev Rep. 2019;15:166-75.

10. Dulak J, Szade K, Szade A, Nowak W, Józkowicz A. Adult stem cells: hopes and hypes of regenerative medicine. Acta Biochim Pol. 2015;62:329-37.

11. Ratajczak MZ, Ratajczak J, Suszynska M, Miller DM, Kucia M, Shin DM. A novel view of the adult stem cell compartment from the perspective of a quiescent population of very small embryonic-like stem cells. Circ Res. 2017;120:166-78.

12. Mallis P, Michalopoulos E, Chatzistamatiou T, Stavropoulos-Giokas C. Mesenchymal stromal cells as potential immunomodulatory players in severe acute respiratory distress syndrome induced by SARS-CoV-2 infection. World J Stem Cells. 2020;12:731-51.

13. Brave $H$, MacLoughlin R. State of the art review of cell therapy in the treatment of lung disease, and the potential for aerosol delivery. Int J Mol Sci. 2020;21:6435

14. Shin DM, Liu R, Klich I, Ratajczak J, Kucia M, Ratajczak MZ. Molecular characterization of isolated from murine adult tissues very small embryonic/ epiblast like stem cells (VSELs). Mol Cells. 2010;29:533-8.

15. Havens AM, Sun H, Shiozawa Y, Jung Y, Wang J, Mishra A, et al. Human and murine very small embryonic-like cells represent multipotent tissue progenitors, in vitro and in vivo. Stem Cells Dev. 2014;23:689-701.

16. UAE Patent. Ventura-Carmenate Y, Bencomo-Hernández A, Alkaabi F, Inventors. Abu Dhabi Stem Cells Center, Assignee. Simplified methods for harvesting non-hematopoietic enriched stem cells cocktail (PBNHESCC) from adult peripheral blood. United Arabe Emirates Patent 3263. 2020-04-302007.

17. WHO. Laboratory testing of human suspected cases of novel coronavirus (nCoV) infection. Geneva WHO; 2020.

18. WHO. WHO R\&D blueprint novel coronavirus COVID-19 therapeutic trial synopsis. Geneva: WHO; 2020.

19. Ortho Clinical Diagnostics. VITROS immunodiagnostic products antiSARS-CoV-2 total / CoV-2-G reagent pack and VITROS immunodiagnostic products anti-SARS- CoV-2 total / CoV-2-G calibrator instructions for use. Version 1.0. Rochester, New York: Ortho Clinical Diagnostics; 2020.

20. Kooraki S, Hosseiny M, Myers L, Gholamrezanezhad A. Coronavirus (COVID-19) outbreak: what the department of radiology should know. J Am Coll Radiol. 2020;17:447-51.

21. U.S. Department of Health and Human Services. Common terminology criteria for adverse events (CTCAE) Version 5.0. 2017. https://ctep.cancer gov/protocoldevelopment/electronic_applications/docs/ctcae_v5. Accessed 17 June 2020

22. GraphPad Software. Analyze categorical data. https://www.graphpad com/quickcalcs/catMenu. Accessed 17 Apr 2020

23. MedCalc ${ }^{\circledR}$ Statistical Software version 20 (MedCalc Software Ltd, Ostend, Belgium; https://www.medcalc.org; 2021). Accessed 17 Apr 2021.

24. UAE Ministry of Health and Prevention (MOHPA). National guidelines for clinical management and treatment of COVID-19. 2020. https://www. dhcr.gov.ae/_layouts/15/download.aspx?SourceUrl=/Documents/LawsA ndRegulations/Circulars/National\%20Guidelines\%20for\%20Clinical\% 20Management\%20and\%20Treatment\%20of\%20COVID-19_V2_English. pdf. Accessed 17 June 2020

25. WHO. Clinical management of COVID-19. Geneva:WHO; 2020

26. Al-Salameh A, Lanoix JP, Bennis Y, Andrejak C, Brochot E, Deschasse G, et al. The association between body mass index class and coronavirus disease 2019 outcomes. Int J Obes. 2020;45:700-5.

27. Alvarez P, Carrillo E, Vélez C, Hita-Contreras F, Martínez-Amat A, RodríguezSerrano F, et al. Regulatory systems in bone marrow for hematopoietic stem/progenitor cells mobilization and homing. Biomed Res Int. 2013;2013:1-12

28. Kuruca SE, Celik DD, Özerkan D, Erdemir G. Characterization and isolation of very small embryonic-like (VSEL) stem cells obtained from various human hematopoietic cell sources. Stem Cell Rev Rep. 2019;15:730-42.

29. Guerin CL, Guyonnet L, Goudot G, Revets D, Konstantinou M, Chipont A et al. Multidimensional proteomic approach of endothelial progenitors demonstrate expression of KDR restricted to CD19 cells. Stem Cell Rev Rep. 2020;17:639-51.

30. Tang L, Yin Z, Hu Y, Mei H. Controlling cytokine storm is vital in COVID-19. FFront Immunol. 2020;11:570993.

31. Carreras E, Dufour C, Mohty M, Kröger N. The EBMT handbook: hematopoietic stem cell transplantation and cellular therapies. Cham: Springer; 2019

32. Pulito-Cueto V, Remuzgo-Martínez S, Genre F, Mora-Cuesta VM, IturbeFernández D, Fernández-Rozas S, et al. Endothelial progenitor cells as a potential biomarker in interstitial lung disease associated with rheumatoid arthritis. J Clin Med. 2020;9:4098.

33. Mao Q, Chu S, Ghanta S, Padbury JF, De Paepe ME. Ex vivo expanded human cord blood-derived hematopoietic progenitor cells induce lung growth and alveolarization in injured newborn lungs. Respir Res. 2013;14:37

34. Hughes MR, Canals Hernaez D, Cait J, Refaeli I, Lo BC, Roskelley CD, et al. A sticky wicket: defining molecular functions for CD34 in hematopoietic cells. Exp Hematol. 2020;86:1-14.

35. Saalbach A, Anderegg U. Thy-1: more than a marker for mesenchymal stromal cells. FASEB J. 2019:33:6689-96.

36. Gheblawi M, Wang K, Viveiros A, Nguyen Q, Zhong J-C, Turner AJ, et al Angiotensin-converting enzyme 2: SARS-CoV-2 receptor and regulator of the renin-angiotensin system. Circ Res. 2020;126:1456-74.

37. Kuba K, Imai Y, Rao S, Gao H, Guo F, Guan B, et al. A crucial role of angiotensin converting enzyme 2 (ACE2) in SARS coronavirus-induced lung injury. Nat Med. 2005;11:875-9.

38. Ratajczak MZ, Bujko K, Ciechanowicz A, Sielatycka K, Cymer M, MarliczW, et al. SARS-CoV-2 entry receptor ACE2 is expressed on very small CD45precursors of hematopoietic and endothelial cells and in response to virus spike protein activates the Nlrp3 inflammasome. Stem Cell Rev Rep. 2020;17:266-77.

39. Vonarburg C, Loetscher M, Spycher MO, Kropf A, Illi M, Salmon S, et al. Topical application of nebulized human $\lg$, IgA and IgAM in the lungs of rats and non-human primates. Respir Res. 2019;20:99.

40. Brodszki N. Add-on or alone? Inhaled nebulized immunoglobulin reduces upper airway infections: 24 months of real-life experience. Immunotherapy. 2020;12:389-94.

41. Chen N, Zhou M, Dong X, Qu J, Gong F, Han Y, et al. Epidemiological and clinical characteristics of 99 cases of 2019 novel coronavirus pneumonia in Wuhan, China: a descriptive study. Lancet. 2020;395:507-13.

42. Pine AB, Meizlish ML, Goshua G, Chang CH, Zhang H, Bishai J, et al. Circulating markers of angiogenesis and endotheliopathy in COVID-19. Pulm Circ. 2020;10:204589402096654.

43. Fan BE, Chong VCL, Chan SSW, Lim GH, Lim KGE, Tan GB, et al. Hematologic parameters in patients with COVID-19 infection. Am J Hematol. 2020;95:E131-4.

44. Algassim AA, Elghazaly AA, Alnahdi AS, Mohammed-Rahim OM, Alanazi $A G$, Aldhuwayhi NA, et al. Prognostic significance of hemoglobin level and autoimmune hemolytic anemia in SARS-CoV-2 infection. Ann Hematol. 2020;100:37-43.

45. Wang D, Hu B, Hu C, Zhu F, Liu X, Zhang J, et al. Clinical characteristics of 138 hospitalized patients with 2019 novel coronavirus-infected pneumonia in Wuhan, China. JAMA. 2020:323:1061-9.

46. Oudelaar BW, Peerbooms JC. Huis in't veld R, Vochteloo AJH. Concentrations of blood components in commercial platelet-rich plasma separation systems: a review of the literature. Am J Sports Med. 2019;47:479-87.

47. Sproston NR, Ashworth JJ. Role of C-reactive protein at sites of inflammation and infection. Front Immunol. 2018;9:754.

48. Kaya B, Sana B, Eris C, Karabulut K, Bat O, Kutanis R. The diagnostic value of D-dimer, procalcitonin and CRP in acute appendicitis. Int J Med Sci. 2012;9:909-15.

49. Bisoendial RJ, Boekholdt SM, Vergeer M, Stroes ESG, Kastelein JJP. C-reactive protein is a mediator of cardiovascular disease. Eur Heart J. 2010:31:2087-91.

50. Li X, Liu C, Mao Z, Xiao M, Wang L, Qi S, et al. Predictive values of neutrophil-to-lymphocyte ratio on disease severity and mortality in COVID-19 patients: a systematic review and meta-analysis. Crit Care. 2020;24:647.

51. Havens AM, Shiozawa Y, Jung Y, Sun H, Wang J, McGee S, et al. Human very small embryonic-like cells generate skeletal structures, in vivo. Stem Cells Dev. 2013;22:622-30. 
52. 'Aver'yanov AV, Konoplyannikov AG, Antonov NS, Osipova GL, 'Vasil'eva OS, Sakharova MG, et al. Survival of mesenchymal stem cells in different methods of nebulization. Bull Exp Biol Med. 2018;164:576-8.

53. Kim SY, Burgess JK, Wang Y, Kable EPW, Weiss DJ, Chan HK, et al. Atomized human amniotic mesenchymal stromal cells for direct delivery to the airway for treatment of lung injury. J Aerosol Med Pulm Drug Deliv. 2016;29:514-24

54. Leng Z, Zhu R, Hou W, Feng Y, Yang Y, Han Q, et al. Transplantation of ACE2- mesenchymal stem cells improves the outcome of patients with COVID-19 pneumonia. Aging Dis. 2020;11:216-28.

55. Barkama R, Mayo A, Paz A, Solopov A, Mann T, Vadasz Z, et al. Placentaderived cell therapy to treat patients with respiratory failure due to coronavirus disease 2019. Crit Care Explor. 2020;2:e0207.

56. Lanzoni G, Linetsky E, Correa D, Messinger Cayetano S, Alvarez RA, Kouroupis $D$, et al. Umbilical cord mesenchymal stem cells for COVID -19 acute respiratory distress syndrome: a double-blind, phase 1/2a, randomized controlled trial. Stem Cells Transl Med. 2021;10:660-73.

\section{Publisher's Note}

Springer Nature remains neutral with regard to jurisdictional claims in published maps and institutional affiliations.
Ready to submit your research? Choose BMC and benefit from:

- fast, convenient online submission

- thorough peer review by experienced researchers in your field

- rapid publication on acceptance

- support for research data, including large and complex data types

- gold Open Access which fosters wider collaboration and increased citations

- maximum visibility for your research: over $100 \mathrm{M}$ website views per year

At BMC, research is always in progress.

Learn more biomedcentral.com/submissions 